\title{
Executive control in frontal lesion aphasia: Does verbal load matter?
}

Article

Accepted Version

Creative Commons: Attribution-Noncommercial-No Derivative Works 4.0

Kendrick, L. T., Robson, H. and Meteyard, L. (2019) Executive control in frontal lesion aphasia: Does verbal load matter? Neuropsychologia, 133. 107178. ISSN 0028-3932 doi: https://doi.org/10.1016/j.neuropsychologia.2019.107178 Available at https://centaur.reading.ac.uk/86145/

It is advisable to refer to the publisher's version if you intend to cite from the work. See Guidance on citing.

To link to this article DOI:

http://dx.doi.org/10.1016/j.neuropsychologia.2019.107178

Publisher: Elsevier

All outputs in CentAUR are protected by Intellectual Property Rights law, including copyright law. Copyright and IPR is retained by the creators or other copyright holders. Terms and conditions for use of this material are defined in the End User Agreement.

www.reading.ac.uk/centaur

\section{CentAUR}

Central Archive at the University of Reading 
Reading's research outputs online 
EXECUTIVE CONTROL IN FRONTAL LESION APHASIA: DOES VERBAL LOAD

MATTER?

Luke T. Kendrick ${ }^{1,2 *}$, Holly Robson ${ }^{2}, \&$ Lotte Meteyard $^{2}$

${ }^{1}$ Department of Psychology, Royal Holloway University of London.

${ }^{2}$ School of Psychology and Clinical Language Sciences, University of Reading.

*Corresponding Author:

Dr Luke T. Kendrick

Department of Psychology,

Royal Holloway University of London,

Egham,

Surrey, TW20 0EX

luke.kendrick@rhul.ac.uk 


\begin{abstract}
Executive control impairments in aphasia resulting from frontal lesions are expected, given that integrity of frontal regions is critical to executive control task performance. Yet the consistency of executive control impairments in aphasia is poorly understood. This is due to previous studies using only a brief set of measures or failing to account for the high language processing demands of many executive control tasks. This study investigated performance across a series of specific and broad executive control task, whilst comparing differences between low or high verbal task versions. Ten participants with aphasia secondary to left inferior frontal lesions and fifteen age matched controls completed a battery of verbal and low verbal executive control tasks tapping into the three core domains of inhibiting, switching, and updating of working memory. For both controls and participants with aphasia, there was no consistent influence of verbal load on either reaction time or accuracy performance. When compared to controls, participants with aphasia demonstrate a general slowing of responses across all reaction time tasks, and are less accurate on switching and updating tasks. These findings do suggest that language processing is not essential for executive control task performance, given that verbal load does not matter. Furthermore, tasks which involve holding multiple sources of information in mind, such as during switching or updating, are particularly vulnerable in aphasia.
\end{abstract}

Keywords: executive control, aphasia, inhibition, switching, updating. 


\section{Introduction}

Executive control impairments are often overlooked in studies of aphasia, yet are considered to be associated with poorer recovery (Brownsett et al., 2013; Frankel, Penn, \& Ormond-Brown, 2007; Keil \& Kaszniak, 2002; Mayer, Mitchinson, \& Murray, 2017; Simic, Rochon, Greco, \& Martino, 2017). How consistently these impairments occur alongside language difficulties in aphasia is also poorly understood (Keil \& Kaszniak, 2002). The majority of traditional executive control tasks have high verbal processing demands, and task performance in aphasia is confounded by the presence of language impairment (Keil \& Kaszniak, 2002; Miyake, Emerson, \& Friedman, 2000). It is therefore critical to understand how task language demands impact executive control performance. Additionally, people with aphasia demonstrate heterogeneity of the extent and size of their lesions. To say that some individuals with aphasia present with executive control impairments and others do not can only be informative if we are specific about the language symptoms and the lesion profile. To manage these confounds, this study uses specially designed tasks to investigate the nature of executive control impairments in individuals with aphasia resulting from inferior frontal lesions.

Executive control is typically regarded as a macroconstruct consisting of three primary subdomains: inhibiting, switching, and updating of working memory (see Diamond, 2013; Miyake, Friedman, et al., 2000). These subdomains (and the neural networks underlying them) are collectively recruited in order to guide goal driven behaviour, solve complex or novel problems, allow for flexible and adaptive behaviour, and to regulate other cognitive processes (Alvarez \& Emory, 2006; Banich, 2009; Jurado \& Rosselli, 2007; Zelazo, Carter, Reznick, \& Frye, 1997). The neural networks that underlie executive control abilities are highly distributed across frontal, parietal and subcortical structures bilaterally (Alvarez \& Emory, 2006; Duncan \& Owen, 2000; Nee, Wager, \& Jonides, 2007; Wager et 
al., 2005). Consequently, there is both overlap and divergence between the executive control and language networks (Woolgar, Duncan, Manes, \& Fedorenko, 2018; Ye \& Zhou, 2009) and it is likely that some executive control abilities play an important role in supporting some specific language functions including lexical access, sentence comprehension, and semantic cognition (Hussey \& Novick, 2012; Ivanova, Dragoy, Kuptsova, Ulicheva, \& Laurinavichyute, 2015; Jefferies \& Lambon Ralph, 2006; Novick, Trueswell, \& ThompsonSchill, 2010; Pompon, McNeil, Spencer, \& Kendall, 2015). As such, the executive control network is vulnerable to lesions associated with aphasia (Keil \& Kaszniak, 2002) with previous neuropsychological studies reporting deficits in executive control abilities in acute (El Hachioui et al., 2014; Seniów, Litwin, \& Leśniak, 2009) and chronic (Purdy, 2002) aphasia. There is also evidence showing that executive control impairments are associated with both poorer outcomes from therapy, limited generalisation beyond therapy, and reduced functional communication skills (Fillingham, Sage, \& Lambon Ralph, 2005; Fridriksson, Nettles, Davis, Morrow, \& Montgomery, 2006; Lambon Ralph, Snell, Fillingham, Conroy, \& Sage, 2010; Miyake, Emerson, et al., 2000; Ramsberger, 2005; Simic et al., 2017; Yeung \& Law, 2010). However, executive control impairments are not universally identified in aphasia, for example, impairments identified at the group level are not consistently demonstrated across the case series (Murray, 2017; Seniów et al., 2009). These inconsistencies mean that the task of fully understanding how executive control impairments occur in aphasia is a complex one.

It is also problematic that many executive control tasks require spoken output, comprehension of complex task instructions, and processing of highly verbal stimulitherefore establishing the cause(s) of poor performance for participants with aphasia is difficult (Murray \& Ramage, 2000). A number of studies avoid this issue entirely by excluding participants with aphasia when measuring cognitive performance (Wall, Isaacs, 
Copland, \& Cumming, 2015). Another approach is to limit the influence of any language impairments by reducing the verbal load of a task (e.g., Chiou \& Kennedy, 2009; Christensen \& Wright, 2010; El Hachioui et al., 2014; Glosser \& Goodglass, 1990; Hamilton \& Martin, 2005; Kuzmina \& Weekes, 2017; Murray, 2017; Seniów et al., 2009). There is evidence that executive control (and logical reasoning abilities) is spared in some severe cases of aphasia when tested with non-verbal tasks (Fedorenko \& Varley, 2016; Varley, 2014). This dissociation between severe language impairment and preserved executive control abilities indicates that despite the overlap between the networks supporting these two abilities, language processing is not critical to executive control task performance. If this were the case, one would expect the use of highly verbal stimuli (thus placing greater demands on language processing) to have little impact on performance.

A small number of studies have directly compared performance between high and low verbal executive tasks in the same group of participants. These studies show that executive control task performance is largely insensitive to the influence of verbal load, that is to say, performance on higher and lower verbal tasks was equivalent (Kuzmina \& Weekes, 2017; Mayer \& Murray, 2012; Murray, 2017). It might be that once verbal load is controlled, any observed impairment of executive control is not specifically influenced by the domain of language. This is however, contradicted by a single case study reporting a dissociation between impaired verbal inhibition and spared non-verbal inhibition (Hamilton \& Martin, 2005). The reverse pattern has also been reported, with poorer performance reported on a low verbal updating of working memory (n-back) task relative to a higher verbal version of the same task, a possible consequence of participants with aphasia being unable to rapidly assign verbal labels to low verbal stimuli (Christensen \& Wright, 2010). The weight of the evidence to date suggest that language processing is non-essential for executive control task 
performance, given that executive control task performance appears to be largely insensitive to the presence of verbal stimuli (and thus increased language processing).

A limitation of many previous studies is an over reliance on broad executive control tasks. Here, the term broad refers to tasks that do not primarily aim to tap into a specific subdomain of executive control, but provide an overall index of executive control performance. For example, the Wisconsin Card Sort Task (WCST) and Raven's Coloured Progressive Matrices (RPCM) are two commonly used measures in studies of individuals with aphasia (Fonseca, Ferreira, \& Martins, 2016) and place demands on multiple aspects of executive control simultaneously (Miyake, Friedman, et al., 2000; Roca et al., 2009). In contrast, Stroop or Flanker tasks tap primarily into inhibiting abilities. For studies that use broader measures, it is difficult to identify if a particular subdomain of executive control is more vulnerable in frontal aphasia, or if multiple subdomains are affected. Understanding how these subdomains can be impaired in aphasia is critical, given that some recent studies have demonstrated a relationship between specific subdomains and different aspects of language function. For example, there are studies demonstrating that impairments of inhibiting are associated with poorer speech production (Hussey \& Novick, 2012; Novick et al., 2010; Schnur, Schwartz, Brecher, \& Hodgson, 2006) and impairments of updating of working memory can be associated with poorer comprehension (Salis, 2012; Salis, Hwang, Howard, \& Lallini, 2017). In order to evaluate such hypotheses, any investigation of executive control in aphasia should target the specific components of inhibiting, updating of working memory, and switching (Miyake, Friedman, et al., 2000).

The aim of this study was to systematically investigate task performance for the three subdomains of executive control in frontal lesion aphasia, using both higher and lower verbal task versions. In addition, these tasks will be adapted to remove possible influences of language impairment (i.e., no need for spoken output on any task). The first research question 
examined if executive control task performance is accounted for or influenced by either high or low verbal stimuli, even where no spoken output is required. Critically, tasks were matched as closely as possible except for a difference in stimuli. For verbal tasks, stimuli were words, letters, numbers or nameable pictures. For low verbal versions, stimuli were symbols, spatial locations, or non-nameable/novel pictures. Equivalent performance in both verbal and low verbal would indicate that language processing is not essential to executive control task performance. Poorer performance in verbal relative to low verbal task versions would indicate that the presence of language impairment is an additional contributor to poor executive control task, and that observed deficits of executive control might be restricted to the domain of language. Poorer performance in low verbal relative to verbal task versions might indicate that participants with aphasia are unable to rapidly assign verbal labels to low verbal material — implying that access to intact language processing is essential for executive control task performance. The second research question examined if the different subdomains of executive control are differentially impaired in frontal lesion aphasia by administering a series of both specific (inhibiting, switching, updating; (Miyake, Friedman, et al., 2000) and broad executive control tasks.

\section{Method}

\section{Ethics and Open Science}

This study received ethical clearance from the School of Psychology and Clinical Language Sciences, University of Reading (Ref: 2015-021-LM). All participants provided informed consent prior to taking part in the study. Adapted aphasia friendly consent and information forms were used for participants with aphasia (PWA). Raw data and R scripts used for analyses of the computerised inhibiting, switching, and updating tasks are available on the Open Science Framework (https://osf.io/92e56/). 


\section{Participants}

Ten participants with post-stroke aphasia $\left(M_{\mathrm{AGE}}=64.27\right.$ years, $\left.S D=8.12\right)$ and fifteen control participants $\left(M_{\mathrm{AGE}}=63.80\right.$ years, $\left.S D=8.04\right)$ took part in the study. Participants with aphasia and controls were matched for age $(t(23)=-0.14, p=.889)$ and years of education $(t(23)=0.80, p=.431)$. Control participants were recruited from the older-adult research panel at the School of Psychology, University of Reading and were within the normal range (score of $\geq 26$ ) on the Montreal Cognitive Assessment. Participants with post-stroke aphasia were recruited through an Aphasia research registry at the School of Clinical Language Sciences, University of Reading. All PWA were at least two years post onset, and one individual was left handed prior to stroke. PWA were screened with the Comprehensive Aphasia Test (Swinburn, Porter, \& Howard, 2004), which consists of a brief cognitive screen and a language assessment (see Table 1 for summary).

\section{Structural Neuroimaging}

3T T1w MRI scans were available for nine participants with aphasia. Lesions were manually drawn on each slice in native space in MRIcron and used for cost-function masking during normalisation. Normalisation was implemented in the SPM clinical toolbox (Rorden, Bonilha, Fridriksson, Bender, \& Karnath, 2012) and normalisation parameters were applied to the native space lesions which were summed to create a lesion overlap map (see Figure 1). At the group level, participants with aphasia displayed maximum lesion overlap (9/9 participants) in the left insula (MNI: $-39,-5,2)$, and left post-central gyrus $(-38,-19,20) .8 / 9$ individuals displayed involvement of the left inferior frontal gyrus $(-53,13,3)$ and 7/9 displayed lesion to the left middle frontal gyrus (-38 34 14). 


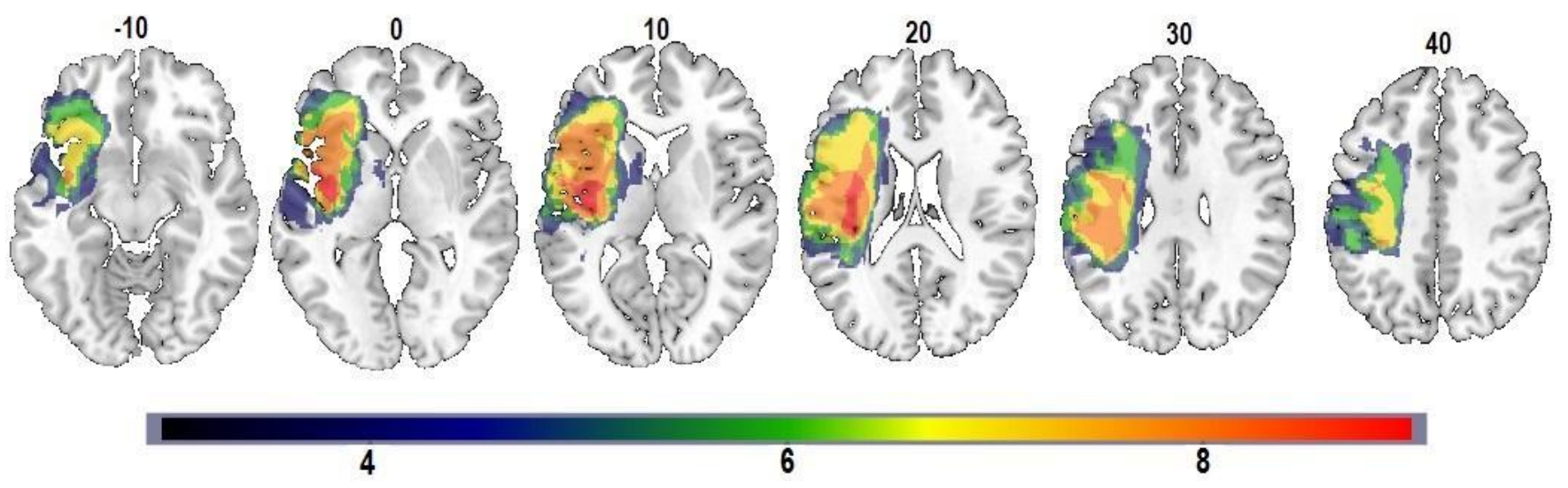

Figure 1. Lesion overlap map for nine PWA. Colour bar indicates number of participants with lesion at each voxel. Overlap image created using MRIcron (Rorden, Karnath, \& Bonilha, 2007). MNI z coordinates are shown above each axial slice. 
Table 1

Demographic Information and Comprehensive Aphasia Test Data for PWA

\begin{tabular}{|c|c|c|c|c|c|c|c|c|c|c|c|c|c|c|}
\hline \multirow[b]{3}{*}{ ID } & \multirow[b]{3}{*}{ Age } & \multirow[b]{3}{*}{ Sex } & \multirow[b]{3}{*}{ Education } & \multirow[b]{3}{*}{ TPS } & \multirow[b]{3}{*}{ CCT } & \multicolumn{9}{|c|}{ Comprehensive Aphasia Test* } \\
\hline & & & & & & \multicolumn{2}{|c|}{ Cognitive Screen } & \multicolumn{2}{|c|}{ Comprehension } & \multicolumn{5}{|c|}{ Spoken Output } \\
\hline & & & & & & $\begin{array}{c}\text { Line } \\
\text { Bisection }\end{array}$ & $\begin{array}{c}\text { Semantic } \\
\text { Memory } \\
(\text { Max 10) }\end{array}$ & $\begin{array}{l}\text { Auditory } \\
\text { (Max 66) }\end{array}$ & $\begin{array}{c}\text { Written } \\
\text { (Max 62) }\end{array}$ & $\begin{array}{l}\text { Verbal } \\
\text { Fluency }\end{array}$ & $\begin{array}{c}\text { Picture } \\
\text { Description }\end{array}$ & $\begin{array}{c}\text { Object } \\
\text { Naming } \\
\text { (Max 48) }\end{array}$ & $\begin{array}{c}\text { Repetition } \\
\text { (Max 74) }\end{array}$ & $\begin{array}{l}\text { Reading } \\
\text { (Max 70) }\end{array}$ \\
\hline P1 & 63 & M & 12 & 12 & $\underline{51}$ & 0 & 10 & $\underline{55}$ & $\underline{48}$ & $\underline{9}$ & $\underline{13}$ & $\underline{40}$ & $\underline{52}$ & $\underline{40}$ \\
\hline P2 & 65 & $\mathrm{~F}$ & 15 & 9 & $\overline{62}$ & 0 & 10 & $\underline{51}$ & $\underline{48}$ & 20 & $\underline{20}$ & $\underline{33}$ & $\underline{47}$ & $\underline{36}$ \\
\hline P3 & 64 & M & 14 & 2 & 59 & -1 & 9 & $\underline{50}$ & $\underline{60}$ & 14 & $\underline{14}$ & $\underline{35}$ & $\underline{6}$ & $\underline{44}$ \\
\hline P4 & 75 & $\mathrm{~F}$ & 10 & 11 & $\underline{52}$ & -1 & 10 & $\underline{51}$ & $\underline{44}$ & $\underline{6}$ & 1 & $\underline{24}$ & $\underline{13}$ & $\underline{14}$ \\
\hline P5 & 72 & $M$ & 17 & 17 & 60 & 1 & 10 & 61 & $\underline{50}$ & 15 & $\underline{17}$ & 44 & 68 & 59 \\
\hline P6 & 49 & $F$ & 11 & 2 & 56 & 0 & $\underline{7}$ & $\underline{53}$ & $\underline{34}$ & 17 & $\underline{13}$ & $\underline{41}$ & $\underline{63}$ & $\underline{42}$ \\
\hline P7 & 68 & $M$ & 13 & 9 & 56 & 0 & $\overline{8}$ & $\overline{58}$ & $\overline{54}$ & $\underline{4}$ & $\overline{8}$ & $\overline{26}$ & $\underline{35}$ & $\overline{32}$ \\
\hline P8 & 57 & $M$ & 15 & 2 & $\underline{50}$ & 0 & 10 & $\overline{63}$ & $\underline{52}$ & $\underline{8}$ & $\underline{7}$ & $\underline{18}$ & $\underline{26}$ & $\underline{28}$ \\
\hline P9 & 55 & $M$ & 15 & 2 & $\underline{45}$ & 0 & 8 & $\underline{32}$ & $\underline{26}$ & $\underline{3}$ & $\underline{8}$ & $\underline{6}$ & $\underline{38}$ & $\underline{0}$ \\
\hline P10 & 70 & $M$ & 16 & 8 & 52 & 0 & 10 & 57 & 52 & 1 & 1 & 19 & 46 & $\underline{0}$ \\
\hline
\end{tabular}

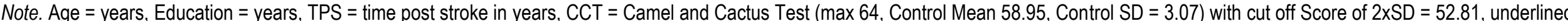
values show participants below cut off. *Scores reported for CAT subtests are raw scores as per criteria set by Swinburn, Porter, \& Howard (2004), underlined values show scores below cut-off (see Swinburn, porter, \& Howard, 2004). 


\section{General Procedure and Apparatus}

All participants completed a battery of executive control tasks containing specific measures of inhibiting (Stroop and Flanker tasks), switching (Shape-Colour Switch Task, Trail Making Task), and updating (N-back tasks, Span tasks), and one broader executive control measure (Wisconsin Card Sorting Test: WCST). These were administered in a randomised order, however, the version of each (verbal or low verbal) was counterbalanced, with half of all participants completing the verbal version first. Tasks were delivered using the E-Prime 2.0 software (Psychology Software Tools, Pittsburgh, PA) with the exception of the Wisconsin Card Sort Task (WCST) which we administered using the bcst-64.pbl script for The Psychology Experiment Building Language (Mueller \& Piper, 2014). Responses for E-Prime tasks were measured by a Serial Response Box (Psychology Software Tools Inc.), with the exception of one (N-Back task) where a computer keyboard response was required. For all computer tasks (except the WCST) participants were given a short practice block prior to each task. All participants were asked to respond to computerised tasks using their left hand, with the exception of the WCST which used a mouse controlled by the examiner (and participants pointed to the screen). Each testing session lasted approximately 90 minutes for controls and 60 minutes for participants with aphasia. Two testing sessions were undertaken with controls and 3-4 sessions were undertaken with participants with aphasia. Data collection was completed within a month.

\section{Stroop Inhibition Tasks}

Both the high and low verbal task versions consisted of three blocks (congruent, neutral, and incongruent), with 48 trials per block. Each trial consisted of a 250msecs fixation followed by the stimulus. The next trial was initiated after the participant made their response, or after 5000msecs (whichever occurred first). In the verbal Stroop, participants were presented with a single word in red, blue, or yellow ink (See Figure 2a). Participants 
were asked to respond to the ink colour using the response box. In the congruent condition, the written word was consistent with the ink colour (i.e., "red" presented in red ink). For the neutral condition, three length matched non-colour words (e.g., dry, fair, worth) were presented in either red, blue, or green ink colour. In the incongruent condition, the word content was inconsistent with the ink colour (i.e., "blue" presented in red ink). For the low verbal Stroop, participants were presented with a single left or right pointing arrow (e.g., $\leftarrow$ or $\rightarrow$; See Figure $2 \mathrm{~b}$ ) and were asked to decide the arrow direction using the response box (left or right buttons). In the congruent condition the arrow direction and position on screen were consistent (i.e., right pointing arrow presented on right side of screen). In the neutral condition, all arrows appeared centre of screen. In the incongruent condition, the arrow direction and arrow position were inconsistent (i.e., left pointing arrow on the right side of screen).

\section{Flanker Inhibition Tasks}

The verbal and low verbal versions of the Flanker tasks consisted of four blocks of 33 trials. Congruent, neutral and incongruent conditions were mixed within each block (11 per condition per block). The trial-to-trial transitions between either congruent or incongruent trials were balanced. This is because an increased number of incongruent to incongruent trialto-trial transitions can reduce incongruence effects (see Mayr, Awh, \& Laurey, 2003). Each trial consisted of a $250 \mathrm{msecs}$ fixation cross followed by the trial stimuli presented until the participant responded or for $5000 \mathrm{msecs}$ (whichever occurred first). Trials were interspersed with 250msecs blank screen. In the verbal Flanker, participants were presented with five letters (e.g., ddddd; See Figure 2c) and asked to identify the central letter using the button response. In the congruent version, the outer letters were consistent with the central letter (e.g., ddddd). In the neural condition the outer letters were replaced with dashes (e.g., - - d - ). In the incongruent condition the outer letters were inconsistent (e.g., bbdbb). In the low 
verbal Flanker, Participants were presented with five arrows (e.g., $\ll<<<$; See Figure 2d) and asked to judge the direction of the centre arrow. In the congruent condition the surrounding arrows were consistent with the central arrow (e.g., $<<<<<)$. In the neural condition the outer arrows were replaced with dashes (e.g., - - > - -). In the incongruent condition the outer arrows were replaced with dashes (e.g., - - > - -). In the incongruent condition the outer arrows were inconsistent with the central arrow (e.g., $<<><<)$.

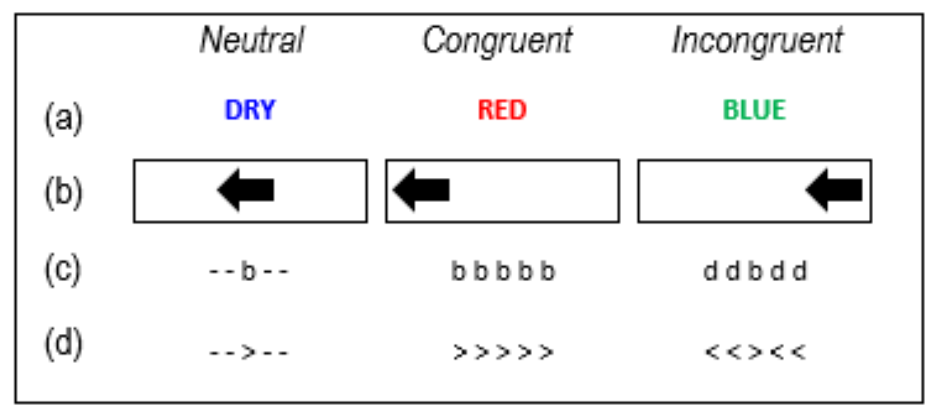

Figure 2. Examples of stimuli used for (a) verbal Stroop (b) low verbal Stroop, (c) verbal Flanker, and (d) low verbal Flanker tasks.

\section{Shape-Colour Switching Task}

Participants were presented with two tiles that contained either patterns (for the low verbal version; See Figure 3a) or numbers (for the verbal version; See Figure 3b). Patterned tiles consisted of one of three possible novel graphical patterns, whereas numbered tiles contained a single digit (1, 2, or 3). These patterns and numbers also varied by colour, either presented in blue, red, or green. In each task version, participants completed blocked tasks. In the first block, participants were presented with tiles and asked to decide if they the colour was the same or different (blocked colour task). In the second block, participants viewed the same tiles; however, decided if the pattern/number (depending on task version) was the same or different (blocked pattern/number task). The third block for each task contained the switching task, where participants were asked to either decide on the colour or the pattern/number. A cue was presented at the top of the screen for each trial, with a coloured 
wheel indicating that the colour decision should be performed, or a grey grid indicating that the pattern/number decision should be performed.

Participants responded using two buttons (yes, no) to indicate their decision. For the switch block, each decision type (colour, pattern/number) was presented in a random task sequence (Monsell, 2003). The initial two blocks (blocked colour and blocked pattern/number) each contained 30 trials in total, with the switch task containing 62 trials in total. In the switch task, there were 31 stay trials (where the participant carried out the same decision as the trial 1-back) and 31 switch trials (where the decision changed from that 1back). For all tasks, each trial was initiated by a 100msecs central fixation cross, followed by the presentation of the stimuli until the participant made a response. Each trial was then followed by a $250 \mathrm{msec}$ blank screen before the next trial began.

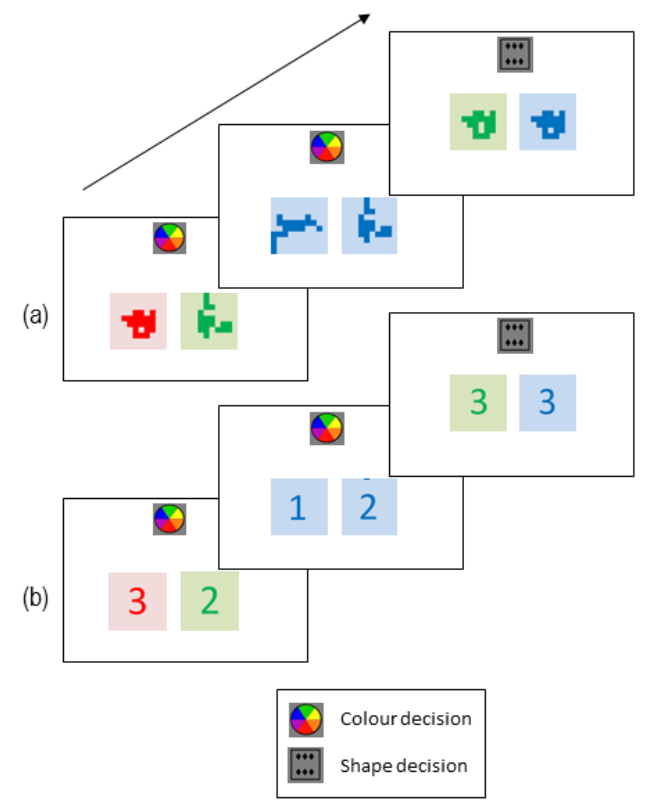

Figure 3. Example trials for (a) low verbal Switching task and (b) verbal switching task.

Panel demonstrates an example from the mixed condition. For blocked conditions participants saw a block of colour decision trials followed by a block of shape decision trials. 


\section{N-Back Updating of Working Memory Tasks}

N-back tasks consisted of three versions, varying on verbal load: digits (verbal), fruit (verbal), and spatial (low verbal), and for each, participants completed both 1-back and 2back version (See Figure 4). In the digits (verbal) version, stimuli consisted of a single number between one and nine. For the fruit (verbal) version, stimuli were nine coloured pictures of high name agreement (>.94) fruit taken from The Bank of Standardised Stimuli (BOSS; Brodeur, Dionne-Dostie, Montreuil, \& Lepage, 2010). Finally, in the spatial (lowverbal) version, stimuli consisted of a blue $2 \mathrm{D}$ square presented in one of nine possible locations on screen (locations consisted of a $3 \times 3$ grid).

During the 1-back task, participants were asked to press a single response button (the spacebar key) when the item they see is "the same as what appeared one trial before, or one back". For the 2-back versions, participants were instructed to respond when the item was the same as what appeared two trials previous, or two back. For the block stimuli, participants were told to monitor the spatial location of the blue square. Each task was divided into four blocks. For the 1-back tasks task blocks one, two, and three consisted of 29 trials, of which nine were targets. Block four consisted of 30 trials, of which nine were targets (overall 117 trials, with 36 targets). For the 2-back task blocks one, two, and three consisted of 28 trials, of which 9 were targets. Block four consisted of 29 trials, of which 9 were targets (overall 113 trials, with 36 targets). Therefore, the trial to target ratio for the 1-back and 2-back tasks were $31 \%$ and $32 \%$ respectively. This is in line with previous n-back paradigms and ensured the task was neither too long or two difficult for either control or patient populations (Christensen \& Wright, 2010). Each trial began with the stimuli presented for 500msecs, followed by a 1500 msecs blank screen meaning participants had $2000 \mathrm{msecs}$ in total to make a response before the next trial appeared. Stimuli were presented in a pseudorandomised order to ensure no more than two hit trials appeared in consecutive trials, and that each type 
of digit, fruit, or spatial location appeared as a target four times across each version of the task.

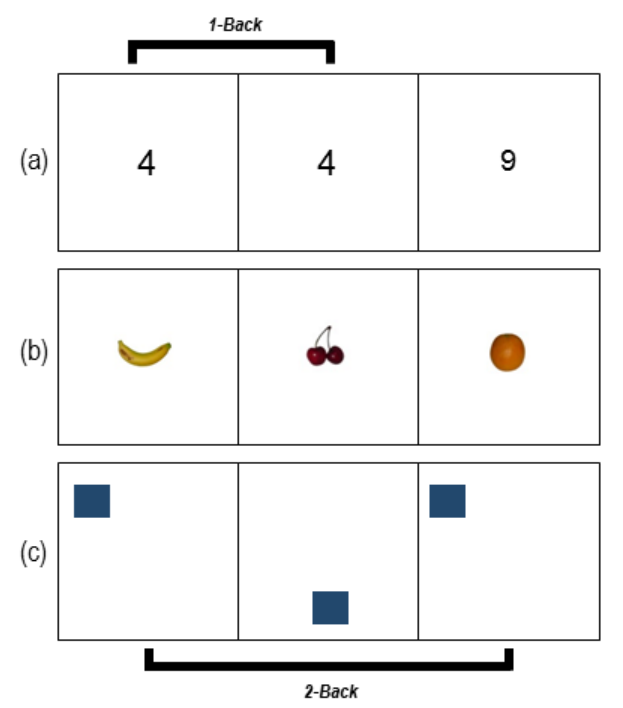

Figure 4. Example stimuli used for the (a) digits, (b) fruit, and (c) spatial n-back task. For the digits and fruit task all stimuli were presented centrally. For the spatial task, a blue square was presented in one of nine possible locations (as per a 3 x 3 grid).

\section{Broader/Traditional Neuropsychological Measures of Executive Control}

Participants also completed three broader/traditional executive control measures. These are briefer measures that are typically used in a clinical setting in order to identify executive control impairments.

Trail Making Test. All participants completed the Trail Making Test, parts A \& B (Lezak, Howieson, Loring, \& Fischer, 2004). This task (in particular Part B) has often been regarded as a measure of switching, however, previous research has suggested that this task also reflects working memory and cognitive flexibility, thus we classified this as a broader executive control task (see Kortte, Horner, \& Windham, 2002; Sanchez-Cubillo et al., 2009; c.f. Arbuthnott \& Frank, 2000). In part A, participants are asked to draw individual lines to connect 25 numbers, in ascending order. In part B, participants are asked to draw individual 
lines between both numbers and letters, alternating between each (e.g., 1-A-2-B-3-C), always in ascending order. Participant response time and errors were recorded.

Span Tasks. Spoken or tapping span tasks are traditionally used as brief measures of working memory in a clinical environment. All participants completed both forwards and backwards digit span and Corsi blocks span tasks. This included the digit span from the Wechsler Memory Scale - Revised (Wechsler, 1981). For the Corsi blocks task, participants were asked to tap out sequence on a series of nine wooden blocks placed in the same position as per Kessels, Van Zandvoort, Postma, Kappelle, and De Haan (2000). In both task versions, the examiner read out or tapped a sequence at a rate of one per second. Participants always completed the forwards version of each task before the backwards version, and the task was discontinued if participants reproduced two incorrect sequences at any given span.

Wisconsin Card Sort Task. Participants also completed Wisconsin Card Sort Task (WCST) which was administered using the bcst-64.pbl script for PEBL (Mueller \& Piper, 2014). In this task participants were presented with a card, which should be categorised by either shape, colour, or number. Participants must use feedback from the task in order to establish which 'rule' is correct (i.e., participant is told after each trial if they were correct/incorrect). After ten successive sorts, the rule changes and participants must adapt and figure out the new rule.

\section{Data Analysis}

All trials less than $250 \mathrm{msecs}$ or greater than $2.5 \mathrm{SD}$ of the mean per participant, per condition were considered mistrials and were subsequently removed. This resulted in a loss of a small amount of data for controls (2.43\% of trials) and participants with aphasia (2.79\%). Removing 2.5 SD per participant, per condition allowed us to capture the individual variability present in the data, whilst retaining power to detect differences in mean RT (Ratcliff, 1993). To decrease positive skew in raw reaction time data, we used a reciprocal (- 
1/RT $T_{\mathrm{SEC}}$ ) transformation (Kliegl, Masson, \& Richter, 2010). Inspection of standardised residual plots per task showed an improvement towards normality using this transformation, relative to the untransformed data. Reaction time data were fit with maximal linear mixed effects (LME) models with crossed-random effects (Baayen, Davidson, \& Bates, 2008; Bates, Mächler, Bolker, \& Walker, 2014). These models examined the effects of group, task type, and condition on participant reaction times. These were performed using the lmerTest package (Kuznetsova, Brockhoff, \& Christensen, 2017) in $R$ version 3.4.0 $R$ version 3.4.0 (https://www.r-project.org/). Each model was fit with all possible main effects and interaction terms (e.g., group x task type x condition) with the maximal random effects structure, in line with a confirmatory hypothesis testing approach for LME models (Barr, Levy, Scheepers, \& Tily, 2013).

Accuracy data from the n-back tasks were fit using parallel maximal generalised linear mixed effects models (GLMM) with binomial link function. Accuracy data for all other tasks were analysed using Mann-Whitney U tests to examine group differences, as there were insufficient number errors to complete GLMM analyses. Full model summaries for response time and accuracy analyses for the Stroop, Flanker, Switching, and N-back tasks are available in the supplementary material. Figures for transformed reaction time data are raincloud plots, created by adapting code from Allen, Poggiali, Whitaker, Marshall, and Kievit (2018).

\section{Results}

\section{Correlations between Tasks}

Correlational analyses between tasks are presented in Appendix A. For the Stroop, Flanker, and Switching tasks, an interference score per participant was used as a ratio between neutral and incongruent reaction times (RT), whilst taking into account baseline neutral performance for potential generalised slowing (i.e., Mean Neutral RT - Mean Incongruent RT / Mean Neutral RT). A larger interference score indicates a slower mean RT 
in the incongruent condition relative to the neutral condition, whereas a value of 0 indicates equivalent performance in both neutral and incongruent conditions. For the n-back tasks, mean d'Prime values were used (higher value indicates better hit and correct rejection performance relative to false alarms and incorrect rejections). For the WCST the number of categories sorted and number of conceptual level responses was included in this analysis. The Trail Making Task was not included due to the high incidence of missing data. Accuracy measures from the computerised tasks were not included due to ceiling performance.

Table A1 (see Appendix) provides the complete set of Spearman's rho correlations between computerised executive control tasks and background measures of language (the CAT) and semantics (Camel and Cactus test) for participants with Aphasia ${ }^{1}$. We applied a Bonferroni correction for multiple comparisons (cut-off $\mathrm{p}=0.003$ ). There was a negative correlation between CAT Auditory Comprehension scores and interference on the Flanker Verbal task $(\mathrm{Rho}=-0.827, \mathrm{p}=0.003)$, indicating better comprehension was associated with better ability to inhibit distractor stimuli. CAT Verbal Fluency scores correlated positively with 2 Back Spatial span $($ Rho $=0.915, \mathrm{p}<0.001)$ and WCST number of categories sorted $($ Rho $=0.841, p=0.002)$. CAT Picture Description correlated positively with 2 Back Spatial span $($ Rho $=0.844, p=0.002)$, with a trend for a positive correlation with 2 Back Fruit span $(\mathrm{Rho}=0.807, \mathrm{p}=0.005)$. It also had a trend for a negative correlation with interference on the Stroop Low Verbal task $($ Rho $=-0.771, p=0.009)$. Finally, CAT Reading scores had a positive correlation with 2 Back Spatial span $(\mathrm{Rho}=0.853, \mathrm{p}=0.001)$ and a negative correlation with interference on the Stroop Low Verbal task (Rho $=-0.839, \mathrm{p}=0.002)$.

\section{Stroop Inhibition Tasks}

\footnotetext{
${ }^{1}$ Tables A2 (for controls) and A3 (for participants with aphasia) show Spearman's rho correlations for computerised executive control tasks. Spearman's rho correlations between computerised tasks and general executive control tasks (with the exception of Trail Making due to insufficient data) for participants with Aphasia are presented in Table A4.
} 
Transformed Stroop reaction times were fit with the following model: $-1 / \mathrm{RT} \sim$ Group*Task Type*Condition $+(1+$ Task Type*Condition $\mid$ Subject $)$. The model revealed significant main effects for group (aphasia, control), task type (high verbal, low verbal), and condition (congruent, neutral, incongruent) on reaction time performance (See Figure 5). Participants with aphasia were overall slower than controls on both task versions and across all conditions $(\beta=-0.29, S E=0.09, t=-3.12, p=.016)$. Both groups were slower on the verbal compared to the non-verbal task $(\beta=-0.71, S E=0.08, t=8.63, p<.001)$. The condition main effects revealed both significant effects of facilitation (i.e., faster performance in congruent vs. neutral $(\beta=-0.17, S E=0.08, t=-2.13, p=.044)$ and incongruence (i.e., slower responses in incongruent vs. congruent $(\beta=-0.53, S E=0.09, t=5.36, p<.001)$. The only significant interaction term was that of task type $\mathrm{x}$ condition (incongruence) $(\beta=-0.28$, $S E=0.11, t=-2.47, p=.021$, with both groups showing greater incongruence effects in the high verbal task version relative to the low verbal task version. In summary, participants with aphasia were generally slower than control participants. The magnitude of the differences between task type and condition did not differ between the two groups (i.e., interactions were not significant) and PWA did not show greater interference effects or a greater influence of verbal vs non-verbal conditions.

For accuracy, there were insufficient data to analyse using generalised GLME models. Mann-Whitney U tests did not reveal significant differences between groups for accuracy rates across all conditions and both task types for the Stroop task once familywise multiple comparisons were accounted for, using a critical p-value of .008 (see Table 2 of Supplementary Material). Both groups reached close to ceiling accuracy rates with $94 \%$ and $96 \%$ for participants with aphasia and controls respectively. 


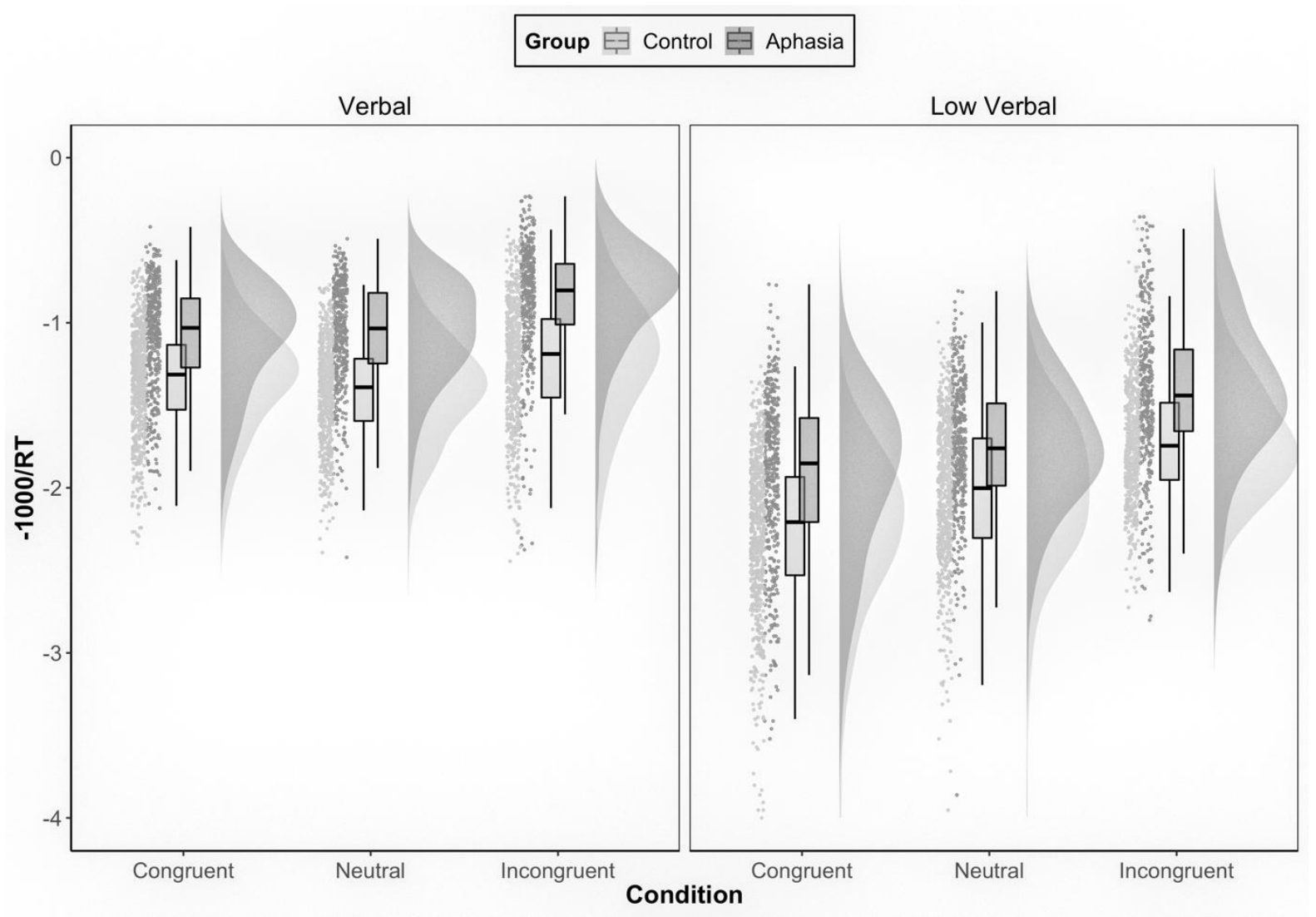

Figure 5. Individual transformed data points, box plots, and distribution plots for verbal and low verbal Stroop tasks. Horizontal line on box plots represents median transformed response time (RT).

\section{Flanker Inhibition Tasks}

Transformed Flanker reaction times were fit with the following model: -1/RT Group*Task Type*Condition $+(1+$ Task Type*Condition $\mid$ Subject $)$. The model revealed significant main effects for group (aphasia, control), condition (congruent, neutral, incongruent), and significant interactions for group x condition (facilitation) and group $\mathrm{x}$ condition (incongruence), see Figure 6. Participants with aphasia were slower than controls on both task versions and across all conditions $(\beta=-0.31, S E=0.10, t=-3.07, \mathrm{p}=.005)$. The condition main effects revealed both slower performance on congruent vs. neutral trials ( $\beta=$ $0.09, S E=0.02, t=3.95, p<.001)$ and slower responses in incongruent vs. congruent trials $(\beta=0.15, S E=0.04, t=4.19, p<.001)$. There were significant group $\mathrm{x}$ condition 
interactions. Control participants showed a larger incongruence effect (i.e., slower in incongruent relative to congruent trials), compared to participants with aphasia $(\beta=-0.17, S E$ $=.05, t=3 . .54, p=.002)$. In summary, participants with aphasia show exaggerated reaction times overall, but these were not influenced by condition or task type. Control participants showed larger interference effects than individuals with aphasia - with greater differences between incongruent and neutral trials.

For accuracy, there were insufficient data to investigate errors using a generalised LME model. Mann-Whitney U tests did not reveal any significant group differences across all conditions and both task types, using a corrected p-value of .01 (see Table 2 Supplementary Material). It was not possible to analyse accuracy rates for the low verbal congruent condition due to lack of variance as all control participants scored $100 \%$. In sum, individuals with aphasia performed with similar accuracy levels to controls. 


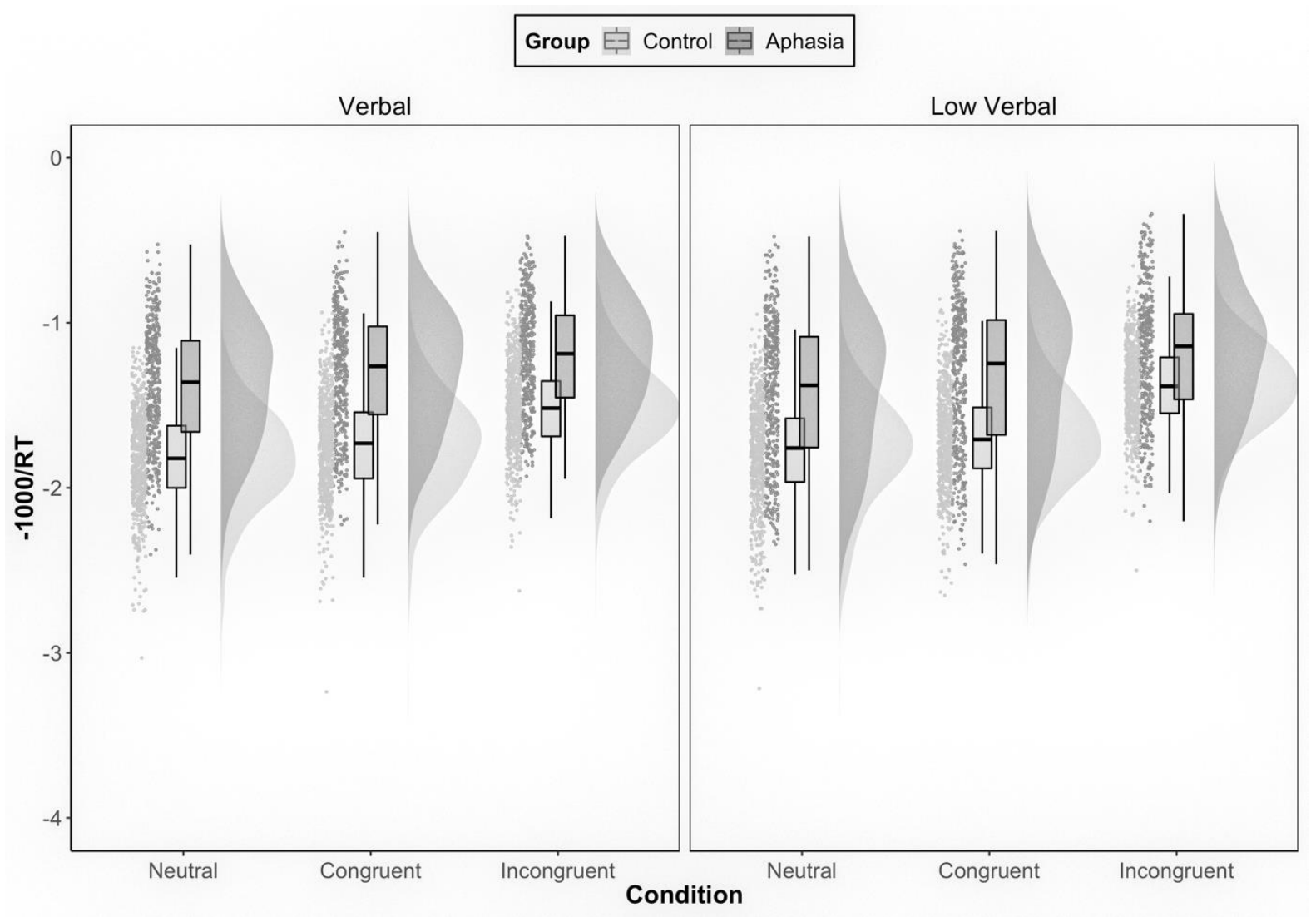

Figure 6. Individual transformed data points, box plots, and distribution plots for verbal and low verbal Flanker tasks. Horizontal line on box plots represents median transformed response time (RT).

\section{Shape-Colour Switch Task}

To examine switch costs (slowing of responses on a switch trial compared to a nonswitch or repeated trial) transformed reaction times were fit with the following model: $-1 / \mathrm{RT}$ $\sim$ Group*Task*TrialType $+(1+$ TaskType*Trial|Subject $)$. The model revealed significant main effects of group (aphasia vs. control) and trial type (repetition vs. switch), see Figure 7. Participants with aphasia produced slower reaction times overall $(\beta=-0.196, S E=0.06, t=-$ $3.23, p=.004)$. Across both groups, switch trials were slower than repetition/stay trials $(\beta=$ $0.05, S E=0.02, t=-2.36, p=.02)$.

To examine mix costs (i.e. the long term cost of switching seen in RTs for mixed vs the blocked conditions) transformed reaction times were fit with the following model:-1/RT 
Group*Task Type*Condition $+(1+$ Task Type*Condition|Subject $)$. The model revealed significant main effects of group (aphasia, control), task type (high-verbal, low-verbal), and condition (blocked, mixed), see Figure 8. Participants with aphasia produced slower reaction times across both task types and condition $(\beta=-0.37, S E=0.08, t=-4.85, p<.001)$. Overall, reaction times were significantly slower in the high verbal compared to low verbal task $(\beta=-$ $0.16, S E=0.05, t=-3.40, p<.002)$. Both groups were significantly slower in the mixed condition compared to the blocked condition $(\beta=0.44, S E=0.06, \mathrm{t}=6.87, p<.001)$. The only significant interaction term was between task type and condition $(\beta=0.11, S E=0.05, t$ $=2.29, p=.031)$, overall both groups were slower in the blocked low verbal tasks compared to the blocked high verbal condition. In summary, participants with aphasia show exaggerated response times but these were not influenced by task type, trial type, or condition.

Accuracy was analysed using Mann-Whitney U tests comparing group performance on the mixed condition across both task types. These revealed one significant group difference when using a corrected critical p-value of .0125 (see Supplementary Material Table 4). Participants with aphasia were significantly less accurate compared to controls on the high-verbal mixed condition $(U=28.5, p=.01)$. Overall, $6 \%$ of all responses on this task were errors, and overall accuracy rates were $89 \%$ and $97 \%$ for participants with aphasia and controls respectively. 


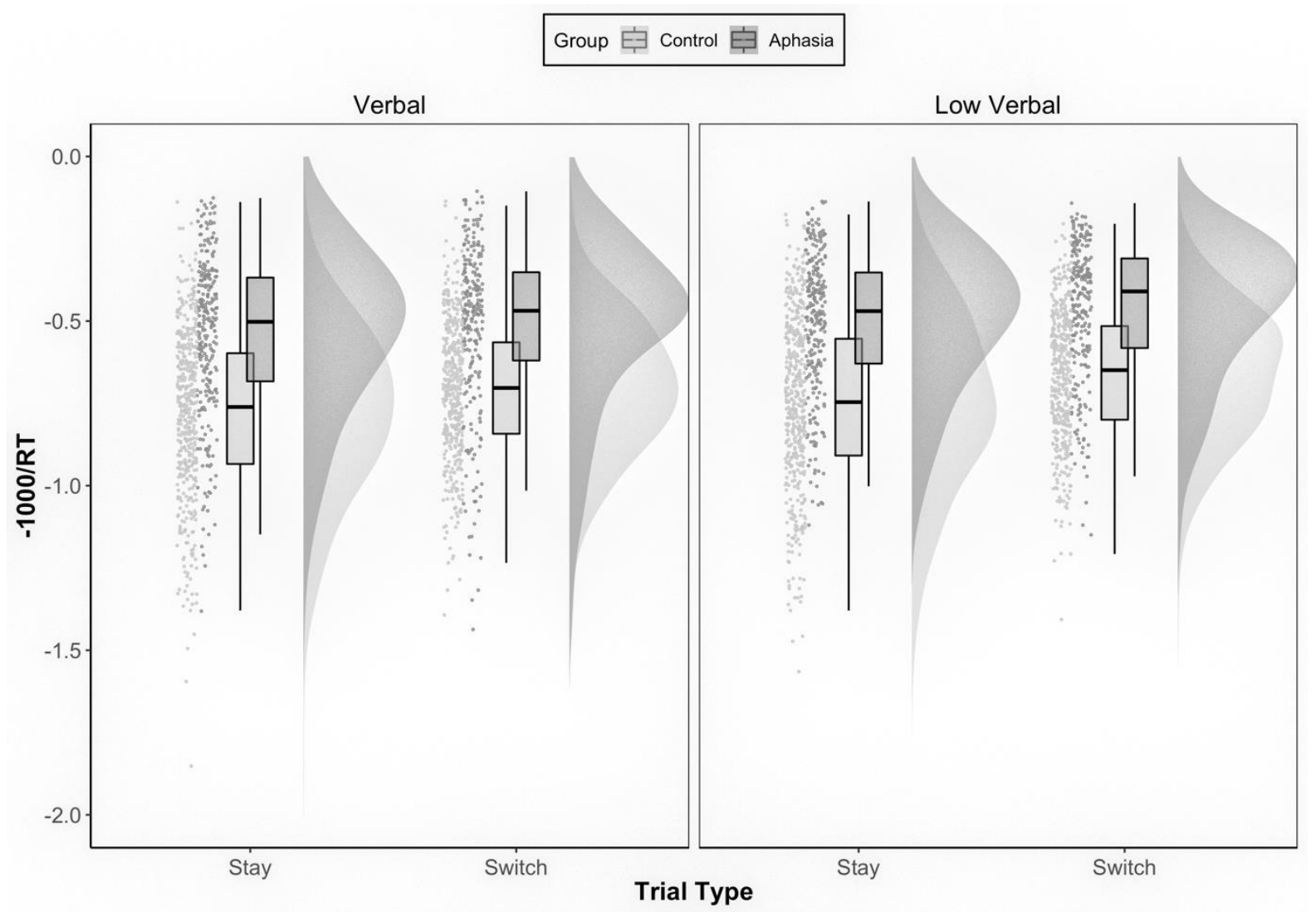

Figure 7. Individual transformed data points, box plots, and distribution plots for verbal and low verbal switch tasks, showing trial types (stay vs. switch trials) within the mixed blocks, thus representing a switch cost. Horizontal line on box plots represents median transformed response time $(\mathrm{RT})$. 


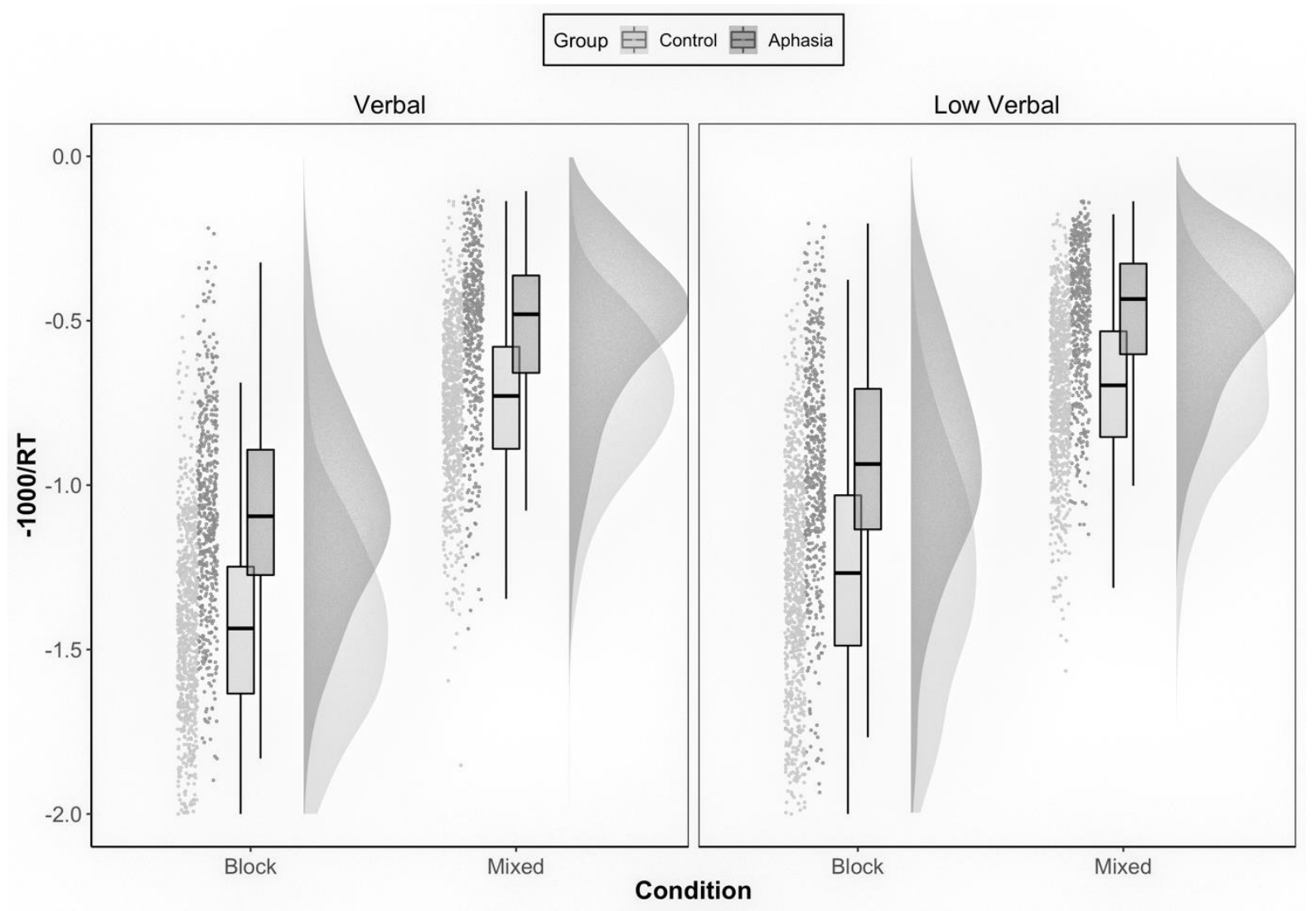

Figure 8. Individual transformed data points, box plots, and distribution plots for verbal and low verbal switch tasks, showing condition types (block vs. mixed conditions), thus showing a mix cost. Horizontal line on box plots represents median transformed response time (RT).

\section{N-Back Updating Tasks}

Accuracy data for hit trials were fit with the following model: HitAccuracy Group*Task Type*Load $+(1+$ Task Type*Load|Subject $)$. The model revealed significant main effects for group (aphasia, control) and load (1-back, 2-back) on the number of correctly identified targets (see Figure 9). Overall, participants with aphasia were less accurate at identifying target trials compared to controls $(\beta=1.32, z=3.05, p=.003)$. All participants were less accurate on the 2-back task relative to the 1 -back task $(\beta=-1.95, z=-$ $8.52, p<.001)$. No other main effect or interaction terms had a significant influence on accuracy. In summary, both groups demonstrated poorer accuracy on 2-back tasks compared 
to 1-back, however, participants with aphasia were overall less accurate than controls on all task versions. Verbal load (fruit, digits, spatial) had no influence on accuracy performance.
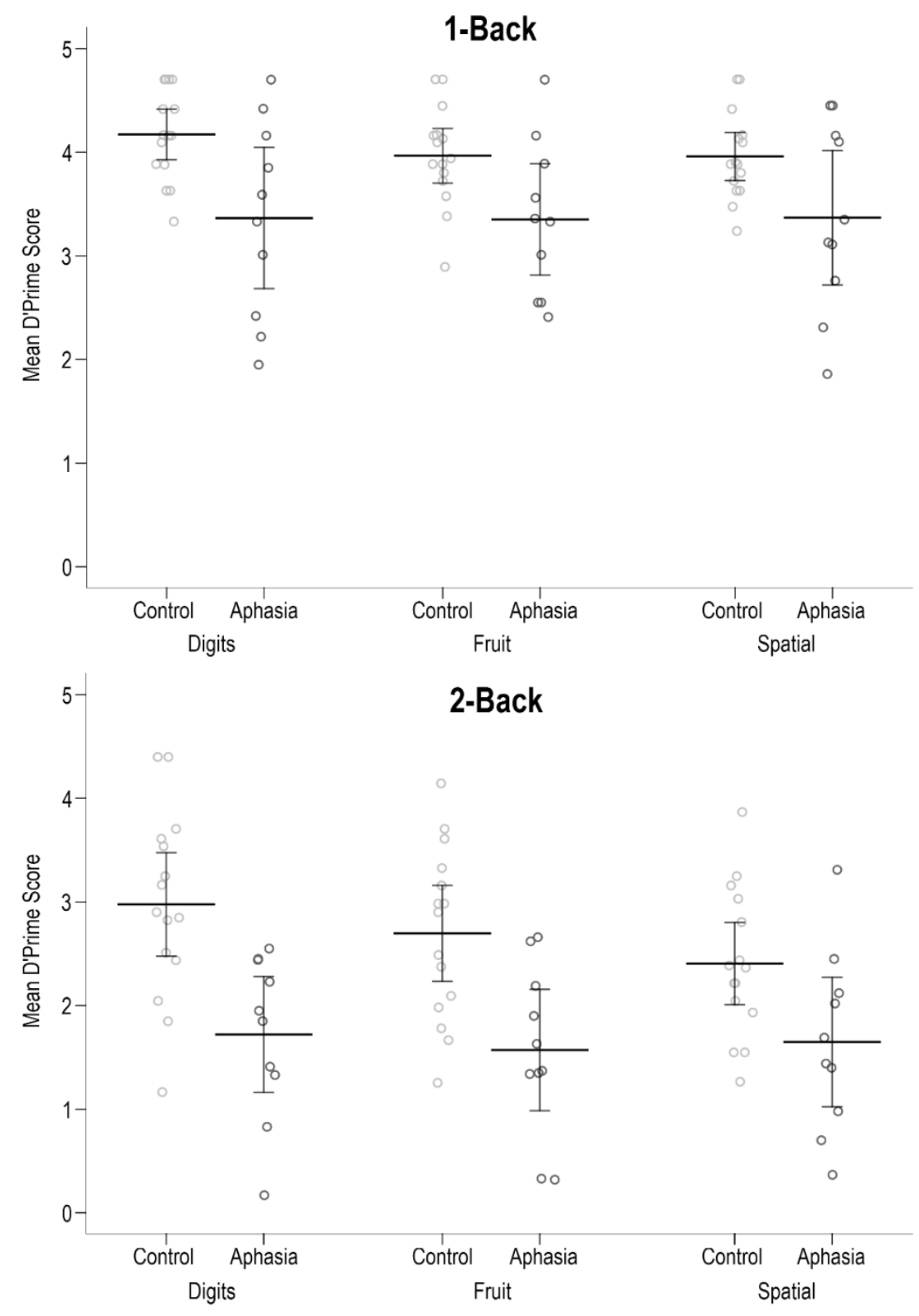

Figure 9. Mean D'Prime values for 1-back (upper) and 2-back (lower) tasks across Digits, Fruit, and Spatial tasks. Error bars represent 95\% confidence intervals. A higher D'Prime score represents better accuracy performance on accuracy trials, whilst also rejecting nontarget trials. 


\section{Trail Making, Span, and WCST Tasks}

Group analyses were not possible for the trail making test (Parts A \& B) as six out of ten participants were unable to complete Part B of the test within the specified time limit. For digit and corsi span tasks we compared groups on both forwards and backwards versions of each task. For both forwards and backwards digits, participants with aphasia produced significantly fewer items (Forwards: $U=2.5, p<.001$; Backwards: $U=6.5, p<.001$ ). Participants with aphasia had a significantly reduced corsi span for forwards $(U=35, p=$ $.038)$ but not backwards $(U=59, p=.514)$ task versions.

For the WCST, we examined group differences on the following measures: number of trials to complete first category, total number of categories sorted, number of correct responses, total errors, number of perseverative errors, number of non-perseverative errors, and number of conceptual level responses. The number of conceptual level responses refers to the number of intentional correct responses, excluding correct answers that occurred by chance. A series of Mann Whitney-U tests revealed no significant group differences on all but one measure, with participants with aphasia producing fewer conceptual level responses compared to control participants $(U=33, p=.032)$. However, this group difference is nonsignificant once significance values are corrected for multiple comparisons (critical $p=.007$ ), see Figure 10. 
Table 2

\begin{tabular}{|c|c|c|c|c|c|c|}
\hline & \multicolumn{2}{|c|}{ Trail Making Testa } & \multicolumn{2}{|c|}{ Corsi Blocks Spanb } & \multicolumn{2}{|c|}{ Spoken Digit Spanb } \\
\hline & Part A & Part B & Forwards & Backwards & Forwards & Backwards \\
\hline $\begin{array}{l}\text { Controls } \\
\text { (SD) }\end{array}$ & $\begin{array}{c}28 \\
(9.23) \\
\end{array}$ & $\begin{array}{c}55 \\
(18.6) \\
\end{array}$ & $\begin{array}{c}6.1 \\
(1.02) \\
\end{array}$ & $\begin{array}{c}4.5 \\
(0.76) \\
\end{array}$ & $\begin{array}{c}6.9 \\
(0.77) \\
\end{array}$ & $\begin{array}{c}4.7 \\
(1.2) \\
\end{array}$ \\
\hline $\mathrm{P} 1$ & 110 & 250 & 4 & 3 & 0 & 0 \\
\hline P2 & 25 & 57 & 7 & 5 & 3 & 3 \\
\hline P3 & 24 & 87 & 7 & 7 & 3 & 0 \\
\hline P4 & $D N C$ & $D N C$ & 3 & 3 & 3 & 0 \\
\hline P5 & 86 & $D N C$ & 4 & 6 & 6 & 3 \\
\hline P6 & 61 & 210 & 4 & 4 & 4 & 4 \\
\hline P7 & 64 & $D N C$ & 5 & 2 & 5 & 2 \\
\hline P8 & 58 & $D N C$ & 5 & 5 & 3 & 2 \\
\hline P9 & $D N C$ & DNC & 6 & 4 & 3 & 0 \\
\hline P10 & 54 & $D N C$ & 5 & 4 & 2 & 2 \\
\hline
\end{tabular}

Note. Controls $=$ Mean value reported, $\mathrm{SD}=$ standard deviation, $\mathrm{DNC}=$ did not complete in specified time. aNumber of seconds taken to complete task. bNumber of items recalled correctly. Controls $n=14$.

Accuracy Data for Trail Making, Corsi Blocks, and Digit Span Tasks
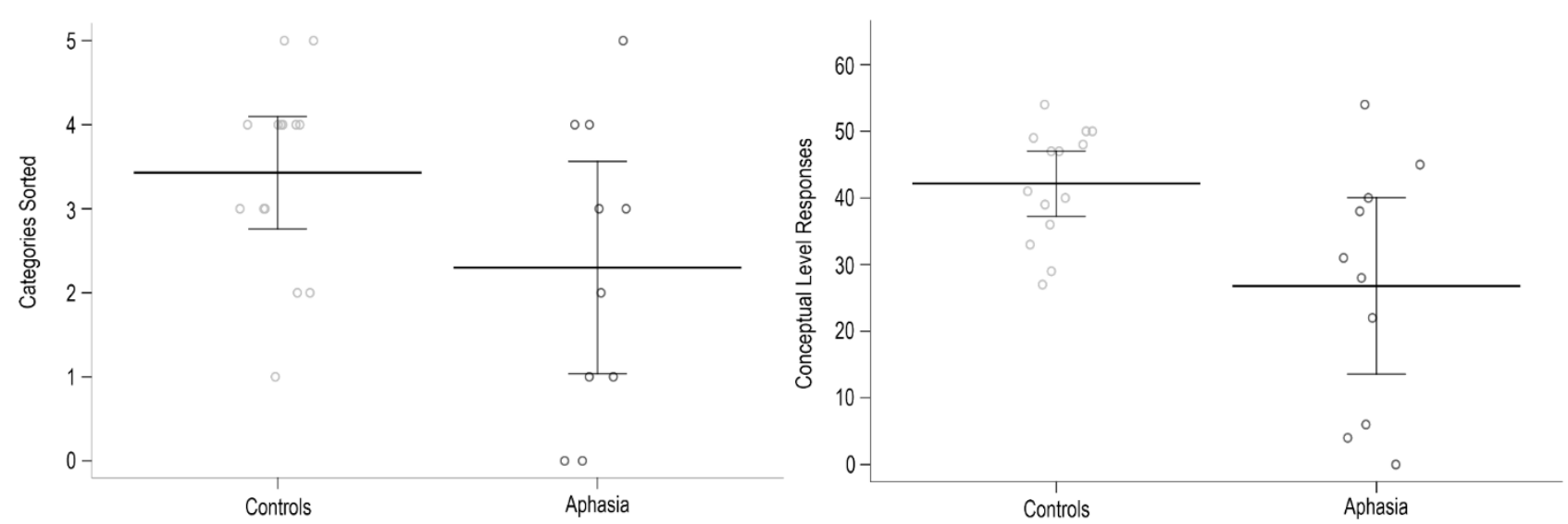

Figure 10. Mean scores for the WCST task on measures of number of categories sorted (max score 5, left figure) and number of conceptual level responses (max score 64, right figure).

\section{Case Series Analyses}

Each participant with aphasia was compared to the mean control performance on the Stroop, Flanker, Same-Colour Switching, and n-back tasks using modified t-tests (Crawford, Garthwaite, \& Howell, 2009). Mean reaction time in each condition was compared to that of 
controls, with the exception of the n-back task where conditional d'Prime values were used. Tables 3 and 4 present mean raw data with scores highlighted where they differ significantly from control data (i.e. $\mathrm{p}<.05$ below the control range). These analyses can address both research questions set out in this study. With regards to verbal and low verbal task performance, impaired performance on one task version but spared performance in the other (i.e., impaired verbal but spared low verbal or vice versa) was the exception rather than the norm. For example, P1 (Stroop, Flanker), P2 (Flanker, N-Back), P6 (Switching), P7 (Stroop), P10 (Stroop, N-Back) demonstrated an association in either direction (See Tables 3 and 4). The direction of this dissociation (i.e., impaired verbal with spared non-verbal or spared verbal with impaired non-verbal) was equal across the case series, which supports the group level findings that overall there is no consistent influence of verbal load. It is important to note that some participants presented with particular difficulty with spatial stimuli (i.e., P10 on Stroop and N-Back), that is, despite the presence of language impairment and lower verbal task demands, this participant still had difficulty with these executive control tasks.

Secondly, if the subdomains of executive control are impaired we would expect to see consistent impairment in executively demanding conditions (e.g., incongruent, mixed, or 2back conditions) with spared performance in the control conditions (baseline/low executively demanding conditions e.g., neutral/congruent, blocked, or 1-back conditions). For example, in the low-verbal Stroop task (Table 3) P9 showed a clear pattern of worse performance in the incongruent condition but spared performance in neutral and control conditions. In addition P5 performed significantly poorer in mixed conditions of switch tasks but not in blocked conditions. However, overall, this pattern of performance was rare as the majority of other cases presented with impairment of baseline conditions in addition to executive impairment (e.g., P4), baseline condition impairment only (e.g., P1), or spared performance entirely (e.g., P3, P8). This is in line with the group level findings indicating that for reaction 
time, specific impairments of executive control were the exception rather than the norm, given participants frequently demonstrated impaired performance on baseline conditions. 
Table 3

Case Series Mean Reaction Time (Msecs) Performance per Condition on Stroop, Flanker, and Switching Tasks

\begin{tabular}{|c|c|c|c|c|c|c|c|c|c|c|c|c|c|c|c|c|}
\hline & \multicolumn{6}{|c|}{ Stroop } & \multicolumn{6}{|c|}{ Flanker } & \multicolumn{4}{|c|}{ Switching } \\
\hline & \multicolumn{3}{|c|}{ Verbal } & \multicolumn{3}{|c|}{ Low Verbal } & \multicolumn{3}{|c|}{ Verbal } & \multicolumn{3}{|c|}{ Low Verbal } & \multicolumn{2}{|c|}{ Verbal } & \multicolumn{2}{|c|}{ Low Verbal } \\
\hline & Con & $\mathrm{Neu}$ & Incon & Con & $\mathrm{Neu}$ & Incon & Con & Neu & Incon & Con & Neu & Incon & Block & Mix & Block & Mix \\
\hline $\mathrm{P} 1$ & $\underline{1137}$ & $\underline{1191}$ & 1294 & 567 & 558 & 708 & $\underline{793}$ & $\underline{764}$ & 879 & 625 & 619 & 723 & 947 & 1899 & 1156 & 1508 \\
\hline P2 & 633 & 838 & 1324 & 511 & 551 & 678 & 682 & 624 & 784 & 860 & $\underline{860}$ & $\underline{809}$ & 816 & 1641 & 823 & 1508 \\
\hline P3 & 882 & 869 & 910 & 401 & 511 & 621 & 604 & 571 & 670 & 571 & 559 & 652 & 897 & 2149 & 956 & 2322 \\
\hline P4 & 1042 & $\underline{1229}$ & $\underline{1468}$ & $\underline{715}$ & $\underline{787}$ & $\underline{1135}$ & $\underline{1011}$ & $\underline{937}$ & $\underline{1192}$ & $\underline{1289}$ & $\underline{1177}$ & $\underline{1748}$ & $\underline{1168}$ & 1068 & $\underline{1854}$ & 1497 \\
\hline P5 & 1135 & $\underline{1074}$ & 1311 & $\underline{671}$ & 552 & 616 & $\underline{944}$ & $\underline{887}$ & $\underline{949}$ & $\underline{944}$ & $\underline{887}$ & 949 & 987 & $\underline{4507}$ & 1279 & $\underline{3955}$ \\
\hline P6 & 1099 & 882 & 1271 & 503 & 524 & 719 & $\underline{887}$ & $\underline{788}$ & 889 & $\underline{1056}$ & $\underline{810}$ & $\underline{1184}$ & 1010 & 2094 & $\underline{1755}$ & $\underline{3433}$ \\
\hline $\mathrm{P} 7$ & $\underline{1314}$ & $\underline{1255}$ & $\underline{1672}$ & 506 & 573 & 721 & 640 & 608 & 659 & 618 & 601 & 732 & 1015 & 2232 & 1015 & 2021 \\
\hline P8 & 944 & 866 & 1058 & 541 & 564 & 769 & 637 & 620 & 672 & 510 & 488 & 596 & 861 & 2140 & 1260 & 2709 \\
\hline P9 & 1070 & $\underline{1080}$ & $\underline{2667}$ & 442 & 582 & $\underline{979}$ & $\underline{1173}$ & $\underline{1009}$ & $\underline{1261}$ & $\underline{981}$ & $\underline{918}$ & $\underline{1250}$ & $\underline{1464}$ & 1994 & $\underline{1568}$ & 2587 \\
\hline P10 & 770 & 929 & 1209 & $\underline{656}$ & $\underline{762}$ & $\underline{1139}$ & $\underline{978}$ & $\underline{1029}$ & $\underline{1102}$ & $\underline{1037}$ & $\underline{883}$ & $\underline{1039}$ & $\underline{1048}$ & 4216 & 967 & 3366 \\
\hline
\end{tabular}

Note. Mean response times that were significantly slower than controls are denoted by bold underlined text. Cut-off was determined using Crawfords modified t-tests (one-tailed), the values beyond cut-off demonstrate that a participant was in the lower estimated $5^{\text {th }}$ percentile $(p<.005)$ of control performance. Con $=$ Congruent, Neu $=$ Neutral, Incon $=$ Incongruent. 
Table 4

Case Series D'Prime Scores per Condition on N-back Tasks

\begin{tabular}{|c|c|c|c|c|c|c|}
\hline & \multicolumn{6}{|c|}{ N-Back } \\
\hline & \multicolumn{2}{|c|}{ Digits } & \multicolumn{2}{|c|}{ Fruit } & \multicolumn{2}{|c|}{ Spatial } \\
\hline & 1 & 2 & 1 & 2 & 1 & 2 \\
\hline P1 & 3.85 & 2.55 & 3.89 & 2.19 & 4.1 & 1.69 \\
\hline P2 & $\underline{3.33}$ & 1.41 & $\underline{3.01}$ & 2.66 & 3.35 & 2.45 \\
\hline P3 & 4.7 & 2.44 & 4.7 & 2.62 & 4.45 & 3.31 \\
\hline P4 & $\underline{3.01}$ & 1.95 & $\underline{2.55}$ & $\underline{0.32}$ & $\underline{1.86}$ & 1.4 \\
\hline P5 & 4.16 & 2.45 & 3.56 & 1.9 & 4.45 & 2.12 \\
\hline P6 & $\underline{2.22}$ & $\underline{1.33}$ & 3.36 & 1.35 & $\underline{3.13}$ & 2.02 \\
\hline P7 & $\underline{1.95}$ & 0.17 & 2.41 & 0.33 & 2.76 & 0.98 \\
\hline P8 & 4.42 & 1.85 & 4.16 & 1.63 & 4.16 & 1.44 \\
\hline P9 & $\underline{2.42}$ & $\underline{0.83}$ & $\underline{2.55}$ & 1.37 & $\underline{2.31}$ & $\underline{0.7}$ \\
\hline P10 & 3.59 & 2.23 & 3.33 & 1.34 & 3.11 & 0.367 \\
\hline
\end{tabular}

Note. Bold and underlined text represents participants who fell significantly below control performance. Cut-off was determined using Crawfords modified t-tests (one-tailed), the values beyond cut-off demonstrate that a participant was in the lower estimated $5^{\text {th }}$ percentile $(p<.005)$ of control performance.

\section{Discussion}

The first research question addressed whether executive control task performance was influenced by either high or low verbal stimuli in a group of participants with frontal lesions and aphasia. Both group level and case-series findings revealed that there were no consistent differences between performance on verbal and low verbal task versions for inhibiting, switching, and updating. This was the case for both reaction time and accuracy analyses, with the exception of accuracy performance for the switching task, revealing a small difference (lower accuracy on verbal compared to low verbal task). The second research question investigated if the different subdomains of executive control were differentially impaired. Given the importance of the frontal lobes for executive control (Alvarez \& Emory, 2006) we expected to see some impairments for our group of participants with aphasia. Overall participants with aphasia demonstrated a generalised slowing in reaction times. For accuracy, participants with aphasia made more errors on switching and updating tasks, suggesting that 
these subdomains may be particularly vulnerable for participants with aphasia and left hemisphere frontal lobe lesions.

\section{When Measuring Executive Control in Aphasia, does verbal load matter?}

The equivalent performance between verbal and low verbal task versions observed in the present study is in line with previous research that has used both group and case-series analyses (Kuzmina \& Weekes, 2017; Murray, 2017). The current study extends these two previous studies by including multiple executive control tasks selected based on previous established theory (e.g., Miyake, Friedman, et al., 2000) and ensuring where possible task versions were comparable (e.g., Kuzmina \& Weekes, 2017). Previously, studies have suggested that the apparent insensitivity of executive control impairments in aphasia to verbal task demands indicates that executive control impairments are domain-general, rather than specific to the language domain (Kuzmina \& Weekes, 2017).

The lack of consistent differences between verbal and low verbal task versions in our data demonstrate that for individuals with frontal lesions and aphasia, a majority of our participants can rely on executive control resources that are independent of whether the stimuli presented are of a verbal or low verbal nature. That is, despite our participants presenting with language deficits, when faced with a verbal executive control task, some participants can rely on their inhibiting, switching, and updating abilities independent of language (see Fedorenko \& Varley, 2016; Varley, 2014).

It is important to note that although efforts were made to reduce the verbal load of low verbal tasks, it is likely that language processing is an important factor for performance on these, for example, left vs. right or same vs. different decisions require elements of language. The tasks used in the present study were as well-matched as possible, with verbal load manipulated via the stimuli displayed (e.g. letters vs arrows, spatial vs. digits). In addition, they did not require verbal output. Whilst it could be argued that this makes the 
verbal manipulation fairly limited, this is precisely the point. When demands from verbal output and complex task instructions are removed, participants with frontal lesions and aphasia show few or no differences between task versions. It is possible (and likely) that executive tasks requiring spoken output would be more impacted by the presence of aphasia (e.g., Hamilton \& Martin, 2005) since lexical retrieval difficulties are one of the most common symptoms in aphasia (Davis, 2007). To our knowledge, one study has demonstrated inconsistent results when directly comparing verbal and low verbal task stimuli. In Christensen and Wright (2010), controls and PWA patterned in the same way, with poorer low verbal task performance, suggesting that results were driven by difficulty assigning verbal labels to highly non-verbal material.

\section{Are different domains of executive control more vulnerable in frontal aphasia?}

Executive control abilities play an important role in supporting specific language functions, such as the relationship between updating and sentence comprehension, or inhibition and lexical retrieval (Hussey \& Novick, 2012; Ivanova et al., 2015; Jefferies, Patterson, \& Ralph, 2008; Novick et al., 2010; Ye \& Zhou, 2009). Therefore, it is important to measure executive control using specific and targeted tasks, tapping into each of these subdomains. On inhibiting and switching tasks, response speed was characterised by a generalised slowing but preserved accuracy, irrespective of condition (i.e., neutral, congruent, incongruent). Therefore, when reaction times are considered, participants with aphasia do not show selective impairments of inhibiting or switching. For the inhibition tasks, this is a pattern that has been reported previously, with exaggerated overall response times but with no impact of incongruence - a pattern necessary to indicate impaired inhibition (Hamilton \& Martin, 2005; Kuzmina \& Weekes, 2017). These studies, however, did find incongruence effects for accuracy. This is potentially a consequence of the increased demands when using spoken versions of a Stroop task. One caveat here is that the removal of spoken output might 
make these tasks easier than usual, particularly where accuracy performance was at ceiling (e.g., on inhibition tasks). However, reaction time data do demonstrate consistent interference effects for both controls and participants with aphasia. Given the lack of spoken output for the tasks in the current study, comparisons with previous studies using different task versions should be made with caution.

The current study's findings are also in line with (Purdy, 2002) who concluded that in aphasia, performance on executive control tasks is characterised by poorer efficiency and response speed in the context of high accuracy. This also raises the important issue of needing to (where possible) interpret accuracy alongside response time. Along with previous research, our data show that on some executive control tasks, participants with aphasia demonstrate speed-accuracy trade-offs (i.e., slowing down to remain accurate at tasks). Future research could assess this by further examining response time as a function of accuracy, as one would expect a higher error rate for trials with faster response times relative to those with slower response times. This finding may also indicate that persons with aphasia might be explicitly strategic when approaching a task (i.e., slowing down in order to remain accurate).

When considering accuracy, our data provides evidence that switching and updating are most vulnerable to frontal lesions in aphasia. For switching, this is in line with previous studies (Chiou \& Kennedy, 2009; Mecklinger, Yves von Cramon, Springer, \& Matthes-von Cramon, 1999). When required to switch responses or mental sets, participants with aphasia are less accurate. The use of computerised switching tasks is rare in studies of aphasia. Instead, the trail making test is used as a brief switching measure, but often yields a high rate of missing data when used for PWA (see Wall, Cumming, \& Copland, 2017), a finding also in line with the present study. We suggest that future research should aim to make use of computerised switching tasks to further explore how shifting between multiple-demands and 
mental sets are impacted in aphasia, and how this might relate to language impairment. It is interesting to note here the potential importance of switching ability for real-world communication, where multiple demands have to be met (Fridriksson et al., 2006).

It is possible that participants with aphasia have difficulty with integrating multiple components to successfully complete the switching task. For example, unlike the inhibition tasks where each trial can be treated independently (i.e., once a selection is made, the participant simply repeats the process on the next trial) the switching task requires keeping in mind multiple task instructions. Reduced performance on this task for PWA may be related to the deployment of multiple skills, or the concurrent use of multiple skills, rather than a deficit in one or more component skills. In the case of switching, participants must keep task instructions in mind, process which task they are required to carry out, process task stimuli, and select the appropriate response. Anecdotally, many participants commented that the switching task was taxing and required greater effort than the other tasks.

For updating, findings from the current study show that participants with aphasia were less accurate at identifying target (or hit) trials in comparison to controls for both 1-back and 2-back tasks. These results are in line with previous work using visual n-back tasks in PWA (Christensen \& Wright, 2010) but contradict those that use auditory task version where significantly greater impairments in 2-back tasks have been identified (Wright, Downey, Gravier, Love, \& Shapiro, 2007). This difference may be a consequence of the transitive nature of auditory stimuli placing a greater weight on phonological STM and executive control processing. Overall, the continuous updating of working memory may be vulnerable in frontal lesion aphasia. It is important to note that the n-back task primarily relies on updating and rapid removal of contents from working memory when necessary, whereas span tasks rely on rehearsal and shifting ability (Ivanova, Kuptsova, \& Dronkers, 2017). 
Finally, we found group differences on the WCST for conceptual level responses, a finding consistent with previous research (Baldo et al., 2005; Baldo, Bunge, Wilson, \& Dronkers, 2010), although this finding did not survive a multiple comparison cut-off. We also found that performance on the WCST correlated with spatial span (see Table A4), indicating that performance on the WCST may reflect capacity in working memory and updating. Span tasks also correlated most often than not with background language measures (see Table A1 and below), reinforcing the finding that working memory is a critical skill for persons with aphasia.

\section{Correlations between Executive Control measures and background measures of}

\section{language}

We found positive correlations between measures of overt speech production (Picture Description, Verbal Fluency, and Reading Aloud) and both working memory span and the WCST (which also loads heavily on memory $\operatorname{span}^{2}$ ). That is, individuals with better working memory performance also scored more highly on overt speech production tasks. Previous research has highlighted an important association between language comprehension and working memory (e.g., Salis et al., 2017). The findings in the current study suggest this association could extend to other language functions, particularly where spatial (or low verbal) working memory is considered. Seniow et al., (2009) suggest that spatial working memory might play an important role in language recovery, given many materials used in therapy are visual (i.e., picture stimuli). In addition, spatial working memory could support the retrieval of semantic knowledge during a language task, for example, keeping in mind visual imagery or the appearance of objects (Baddeley, 2003b). Given the limited sample size in the current study, future research should aim to explore these possible associations.

\footnotetext{
${ }^{2}$ Note that WCST number of categories scored had a significant positive correlation with 2back spatial span (see Table A4).
} 
We also found correlations and trends for correlations between the amount of interference on inhibition tasks and performance in Auditory Comprehension, Picture Description and Reading Aloud. Here, less interference on the inhibition tasks correlated with better language scores. This finding is in line with previous findings that inhibitory skills play a role in speech production (Hussey \& Novick, 2012; Novick et al., 2010; Schnur, Schwartz, Brecher, \& Hodgson, 2006) and also possibly in comprehension assessments where distracters need to be inhibited. Notably, these correlations came from both low verbal (Stroop) and verbal (Flanker) versions of the tasks, indicating that it is domain general inhibitory skills that are of importance.

Finally, despite our attempts to minimise the differences between verbal and low verbal task versions (e.g., same instructions and response types across versions) the correlations between task versions were, for the most part, non-significant (See Table A3). This lack of association indicates that changing task modality leads to the executive control network being differently engaged, potentially because participants change task strategy. This finding questions the ability to generalise between executive control measures which are purported to be measuring the same capacity and suggests that further research is needed to understand the variable use of the executive control network within and beyond aphasia.

\section{Conclusions and Future Directions}

We found that individuals with frontal lesions and aphasia are insensitive to the verbal demands on executive control tasks, where no spoken output is required. These findings suggest that language processing is not necessarily essential for executive control task performance — given that participants with clear language impairment performed equally well on both task versions. The observed generalised slowing in reaction times needs to be considered alongside accuracy performance, in order to evaluate how resources are deployed (i.e., attention and working memory) and how individuals implement different strategies to 
maintain task performance. Finally, our findings suggest that deficits in executive control for people with aphasia might be related to dealing with continuous updating and multiple demands (i.e., the updating and switching tasks) rather than being a broad impairment across all areas of executive control. These findings provide further insight into the cognitive performance of individuals with frontal lesions and aphasia, however, future research should aim to replicate these findings using larger sample sizes, whilst also comparing possible differences between people with aphasia based on lesion profile.

\section{Acknowledgements}

This study was funded by a postgraduate studentship from the University of Reading awarded to LK and a British Academy ARP Scheme Grant (AN140005) awarded to LM and HR. We wish to thank all of the participants who generously gave up their time to take part in this research study. 


\section{References}

Allen, M., Poggiali, D., Whitaker, K., Marshall, T. R., \& Kievit, R. (2018). Raincloud plots: a multi-platform tool for robust data visualization. PeerJ Preprints, 6, e27137v1.

Alvarez, J. A., \& Emory, E. (2006). Executive function and the frontal lobes: a meta-analytic review. Neuropsychology Review, 16(1), 17-42.

Arbuthnott, K., \& Frank, J. (2000). Trail making test, part B as a measure of executive control: validation using a set-switching paradigm. Journal of Clinical and Experimental Neuropsychology, 22(4), 518-528.

Baayen, R. H., Davidson, D. J., \& Bates, D. M. (2008). Mixed-effects modeling with crossed random effects for subjects and items. Journal of Memory and Language, 59(4), 390412.

Baldo, J. V, Bunge, S. A., Wilson, S. M., \& Dronkers, N. F. (2010). Is relational reasoning dependent on language? A voxel-based lesion symptom mapping study. Brain and Language, 113(2), 59-64.

Baldo, J. V, Dronkers, N. F., Wilkins, D., Ludy, C., Raskin, P., \& Kim, J. (2005). Is problem solving dependent on language? Brain and Language, 92(3), 240-250.

Banich, M. T. (2009). Executive function: The search for an integrated account. Current Directions in Psychological Science, 18(2), 89-94.

Barr, D. J., Levy, R., Scheepers, C., \& Tily, H. J. (2013). Random effects structure for confirmatory hypothesis testing: Keep it maximal. Journal of Memory and Language, 68(3), 255-278.

Bates, D., Mächler, M., Bolker, B., \& Walker, S. (2014). Fitting linear mixed-effects models using lme4. ArXiv Preprint ArXiv:1406.5823.

Brodeur, M. B., Dionne-Dostie, E., Montreuil, T., \& Lepage, M. (2010). The Bank of Standardized Stimuli (BOSS), a new set of 480 normative photos of objects to be used 
as visual stimuli in cognitive research. PloS One, 5(5), e10773.

Brownsett, S. L. E., Warren, J. E., Geranmayeh, F., Woodhead, Z., Leech, R., \& Wise, R. J. S. (2013). Cognitive control and its impact on recovery from aphasic stroke. Brain, $137(1), 242-254$.

Chiou, H. S., \& Kennedy, M. R. T. (2009). Switching in adults with aphasia. Aphasiology, 23(7-8), 1065-1075.

Christensen, S. C., \& Wright, H. H. (2010). Verbal and non-verbal working memory in aphasia: What three n-back tasks reveal. Aphasiology, 24(6-8), 752-762.

Crawford, J. R., Garthwaite, P. H., \& Howell, D. C. (2009). On comparing a single case with a control sample: An alternative perspective. Neuropsychologia, 47(13), 2690-2695.

Davis, G. A. (2007). Aphasiology: Disorders and Clinical Practice (2nd. Boston, MA: Allyn \& Bacon.

Diamond, A. (2013). Executive functions. Annual Review of Psychology, 64, 135-168.

Duncan, J., \& Owen, A. M. (2000). Common regions of the human frontal lobe recruited by diverse cognitive demands. Trends in Neurosciences, 23(10), 475-483.

El Hachioui, H., Visch-Brink, E. G., Lingsma, H. F., van de Sandt-Koenderman, M. W. M. E., Dippel, D. W. J., Koudstaal, P. J., \& Middelkoop, H. A. M. (2014). Nonlinguistic cognitive impairment in poststroke aphasia: a prospective study. Neurorehabilitation and Neural Repair, 28(3), 273-281.

Fedorenko, E., \& Varley, R. (2016). Language and thought are not the same thing: evidence from neuroimaging and neurological patients. Annals of the New York Academy of Sciences, 1369(1), 132-153.

Fillingham, J. K., Sage, K., \& Lambon Ralph, M. A. (2005). Treatment of anomia using errorless versus errorful learning: Are frontal executive skills and feedback important? International Journal of Language \& Communication Disorders, 40(4), 505-523. 
Fonseca, J., Ferreira, J. J., \& Martins, I. P. (2016). Cognitive performance in aphasia due to stroke: a systematic review. International Journal on Disability and Human Development, 16(2), 127-139.

Frankel, T., Penn, C., \& Ormond-Brown, D. (2007). Executive dysfunction as an explanatory basis for conversation symptoms of aphasia: A pilot study. Aphasiology, 21(6-8), 814828.

Fridriksson, J., Nettles, C., Davis, M., Morrow, L., \& Montgomery, A. (2006). Functional communication and executive function in aphasia. Clinical Linguistics \& Phonetics, 20(6), 401-410.

Glosser, G., \& Goodglass, H. (1990). Disorders in executive control functions among aphasic and other brain-damaged patients. Journal of Clinical and Experimental Neuropsychology, 12(4), 485-501.

Hamilton, A. C., \& Martin, R. C. (2005). Dissociations among tasks involving inhibition: A single-case study. Cognitive, Affective, \& Behavioral Neuroscience, 5(1), 1-13.

Hussey, E. K., \& Novick, J. M. (2012). The benefits of executive control training and the implications for language processing. Frontiers in Psychology, 3, 158.

Ivanova, M. V, Dragoy, O. V, Kuptsova, S. V, Ulicheva, A. S., \& Laurinavichyute, A. K. (2015). The contribution of working memory to language comprehension: Differential effect of aphasia type. Aphasiology, 29(6), 645-664.

Ivanova, M. V, Kuptsova, S. V, \& Dronkers, N. F. (2017). A comparison of two working memory tasks in aphasia. Aphasiology, 31(3), 265-281.

Jefferies, E., \& Lambon Ralph, M. A. (2006). Semantic impairment in stroke aphasia versus semantic dementia: a case-series comparison. Brain, 129(8), 2132-2147.

Jefferies, E., Patterson, K., \& Ralph, M. A. L. (2008). Deficits of knowledge versus executive control in semantic cognition: Insights from cued naming. Neuropsychologia, 46(2), 
649-658.

Jurado, M. B., \& Rosselli, M. (2007). The elusive nature of executive functions: a review of our current understanding. Neuropsychology Review, 17(3), 213-233.

Keil, K., \& Kaszniak, A. W. (2002). Examining executive function in individuals with brain injury: A review. Aphasiology, 16(3), 305-335.

Kessels, R. P. C., Van Zandvoort, M. J. E., Postma, A., Kappelle, L. J., \& De Haan, E. H. F. (2000). The Corsi block-tapping task: standardization and normative data. Applied Neuropsychology, 7(4), 252-258.

Kliegl, R., Masson, M. E. J., \& Richter, E. M. (2010). A linear mixed model analysis of masked repetition priming. Visual Cognition, 18(5), 655-681.

Kortte, K. B., Horner, M. D., \& Windham, W. K. (2002). The trail making test, part B: cognitive flexibility or ability to maintain set? Applied Neuropsychology, 9(2), 106-109.

Kuzmina, E., \& Weekes, B. S. (2017). Role of cognitive control in language deficits in different types of aphasia. Aphasiology, 31(7), 765-792.

Kuznetsova, A., Brockhoff, P. B., \& Christensen, R. H. B. (2017). lmerTest: tests in Linear mixed effects models. R package version 2.0-33. 2016. Google Scholar.

Lambon Ralph, M. A., Snell, C., Fillingham, J. K., Conroy, P., \& Sage, K. (2010). Predicting the outcome of anomia therapy for people with aphasia post CVA: Both language and cognitive status are key predictors. Neuropsychological Rehabilitation, 20(2), 289-305.

Lezak, M. D., Howieson, D. B., Loring, D. W., \& Fischer, J. S. (2004). Neuropsychological assessment. Oxford University Press, USA.

Mayer, J. F., Mitchinson, S. I., \& Murray, L. L. (2017). Addressing concomitant executive dysfunction and aphasia: previous approaches and the new brain budget protocol. Aphasiology, 31(7), 837-860.

Mayer, J. F., \& Murray, L. L. (2012). Measuring working memory deficits in aphasia. 
Journal of Communication Disorders, 45(5), 325-339.

Mayr, U., Awh, E., \& Laurey, P. (2003). Conflict adaptation effects in the absence of executive control. Nature Neuroscience, 6(5), 450.

Mecklinger, A., Yves von Cramon, D., Springer, A., \& Matthes-von Cramon, G. (1999). Executive control functions in task switching: Evidence from brain injured patients. Journal of Clinical and Experimental Neuropsychology, 21(5), 606-619.

Miyake, A., Emerson, M. J., \& Friedman, N. P. (2000). Assessment of executive functions in clinical settings: Problems and recommendations. In Seminars in speech and language (Vol. 21, pp. 169-183). Copyright@ 2000 by Thieme Medical Publishers, Inc., 333 Seventh Avenue, New York, NY 10001, USA. Tel.:+ 1 (212) 584-4663.

Miyake, A., Friedman, N. P., Emerson, M. J., Witzki, A. H., Howerter, A., \& Wager, T. D. (2000). The unity and diversity of executive functions and their contributions to complex "frontal lobe" tasks: A latent variable analysis. Cognitive Psychology, 41(1), $49-100$.

Monsell, S. (2003). Task switching. Trends in Cognitive Sciences, 7(3), 134-140.

Mueller, S. T., \& Piper, B. J. (2014). The psychology experiment building language (PEBL) and PEBL test battery. Journal of Neuroscience Methods, 222, 250-259.

Murray, L. L. (2017). Design fluency subsequent to onset of aphasia: a distinct pattern of executive function difficulties? Aphasiology, 31(7), 793-818.

Murray, L. L., \& Ramage, A. E. (2000). Assessing the executive function abilities of adults with neurogenic communication disorders. In Seminars in speech and language (Vol. 21, pp. 153-168). THEIME MEDICAL PUBLISHERS INC.

Nee, D. E., Wager, T. D., \& Jonides, J. (2007). Interference resolution: insights from a metaanalysis of neuroimaging tasks. Cognitive, Affective, \& Behavioral Neuroscience, 7(1), $1-17$. 
Novick, J. M., Trueswell, J. C., \& Thompson-Schill, S. L. (2010). Broca's area and language processing: Evidence for the cognitive control connection. Language and Linguistics Compass, 4(10), 906-924.

Pompon, R. H., McNeil, M. R., Spencer, K. A., \& Kendall, D. L. (2015). Intentional and reactive inhibition during spoken-word Stroop task performance in people with aphasia. Journal of Speech, Language, and Hearing Research, 58(3), 767-780.

Purdy, M. (2002). Executive function ability in persons with aphasia. Aphasiology, 16(4-6), $549-557$.

Ramsberger, G. (2005). Achieving conversational success in aphasia by focusing on nonlinguistic cognitive skills: A potentially promising new approach. Aphasiology, 19(1011), 1066-1073.

Ratcliff, R. (1993). Methods for dealing with reaction time outliers. Psychological Bulletin, 114(3), 510 .

Roca, M., Parr, A., Thompson, R., Woolgar, A., Torralva, T., Antoun, N., ... Duncan, J. (2009). Executive function and fluid intelligence after frontal lobe lesions. Brain, 133(1), 234-247.

Rorden, C., Bonilha, L., Fridriksson, J., Bender, B., \& Karnath, H.-O. (2012). Age-specific CT and MRI templates for spatial normalization. Neuroimage, 61(4), 957-965.

Rorden, C., Karnath, H.-O., \& Bonilha, L. (2007). Improving lesion-symptom mapping. Journal of Cognitive Neuroscience, 19(7), 1081-1088.

Salis, C. (2012). Short-term memory treatment: Patterns of learning and generalisation to sentence comprehension in a person with aphasia. Neuropsychological Rehabilitation, $22(3), 428-448$.

Salis, C., Hwang, F., Howard, D., \& Lallini, N. (2017). Short-term and working memory treatments for improving sentence comprehension in aphasia: A review and a replication 
study. In Seminars in speech and language (Vol. 38, pp. 29-39). Thieme Medical Publishers.

Sanchez-Cubillo, I., Perianez, J. A., Adrover-Roig, D., Rodriguez-Sanchez, J. M., Rios-Lago, M., Tirapu, J., \& Barcelo, F. (2009). Construct validity of the Trail Making Test: role of task-switching, working memory, inhibition/interference control, and visuomotor abilities. Journal of the International Neuropsychological Society, 15(3), 438-450.

Schnur, T. T., Schwartz, M. F., Brecher, A., \& Hodgson, C. (2006). Semantic interference during blocked-cyclic naming: Evidence from aphasia. Journal of Memory and Language, 54(2), 199-227.

Seniów, J., Litwin, M., \& Leśniak, M. (2009). The relationship between non-linguistic cognitive deficits and language recovery in patients with aphasia. Journal of the Neurological Sciences, 283(1), 91-94.

Simic, T., Rochon, E., Greco, E., \& Martino, R. (2017). Baseline executive control ability and its relationship to language therapy improvements in post-stroke aphasia: a systematic review. Neuropsychological Rehabilitation, 1-45.

Swinburn, K., Porter, G., \& Howard, D. (2004). Comprehensive aphasia test. Psychology Press.

Varley, R. (2014). Reason without much language. Language Sciences, 46, 232-244.

Wager, T. D., Sylvester, C.-Y. C., Lacey, S. C., Nee, D. E., Franklin, M., \& Jonides, J. (2005). Common and unique components of response inhibition revealed by fMRI. Neuroimage, 27(2), 323-340.

Wall, K. J., Cumming, T. B., \& Copland, D. A. (2017). Determining the association between language and cognitive Tests in Poststroke aphasia. Frontiers in Neurology, 8, 149.

Wall, K. J., Isaacs, M. L., Copland, D. A., \& Cumming, T. B. (2015). Assessing cognition after stroke. Who misses out? A systematic review. International Journal of Stroke, 
$10(5), 665-671$.

Wechsler, D. (1981). WAIS-R manual: Wechsler adult intelligence scale-revised.

Psychological Corporation.

Woolgar, A., Duncan, J., Manes, F., \& Fedorenko, E. (2018). Fluid intelligence is supported by the multiple-demand system not the language system. Nature Human Behaviour, 2(3), 200 .

Wright, H. H., Downey, R. A., Gravier, M., Love, T., \& Shapiro, L. P. (2007). Processing distinct linguistic information types in working memory in aphasia. Aphasiology, 21(68), 802-813.

Ye, Z., \& Zhou, X. (2009). Executive control in language processing. Neuroscience \& Biobehavioral Reviews, 33(8), 1168-1177.

Yeung, O., \& Law, S.-P. (2010). Executive functions and aphasia treatment outcomes: Data from an ortho-phonological cueing therapy for anomia in Chinese. International Journal of Speech-Language Pathology, 12(6), 529-544.

Zelazo, P. D., Carter, A., Reznick, J. S., \& Frye, D. (1997). Early development of executive function: A problem-solving framework. Review of General Psychology, 1(2), 198. 


\section{Appendix A}

\section{Correlations between Tasks}

For the Stroop, Flanker, and Switching tasks, an interference score per participant was used as a ratio between neutral and incongruent reaction times (RT), whilst taking into account baseline neutral performance for potential generalised slowing (i.e., Mean Neutral RT - Mean Incongruent RT / Mean Neutral RT). A larger interference score indicates a slower mean RT in the incongruent condition relative to the neutral condition, whereas a value of 0 indicates equivalent performance in both neutral and incongruent conditions. For the n-back tasks, mean d'Prime values were used (higher value indicates better hit and correct rejection performance relative to false alarms and incorrect rejections). For the WCST the number of categories sorted and number of conceptual level responses was included in this analysis. The Trail Making Task was not included due to the high incidence of missing data. Accuracy measures from the computerised tasks were not included due to ceiling performance. 


\begin{tabular}{|c|c|c|c|c|c|c|c|c|c|c|c|c|c|c|c|c|c|}
\hline & & $\begin{array}{l}\text { Stroop } \\
\text { Verbal }\end{array}$ & $\begin{array}{l}\text { Stroop } \\
\text { Low } \\
\text { Verbal }\end{array}$ & $\begin{array}{l}\text { Flanker } \\
\text { Verbal }\end{array}$ & $\begin{array}{l}\text { Flanker } \\
\text { Low } \\
\text { Verbal }\end{array}$ & $\begin{array}{l}\text { Mix Cost } \\
\text { Verbal }\end{array}$ & $\begin{array}{l}\text { Mix Cost } \\
\text { Low } \\
\text { Verbal }\end{array}$ & $\begin{array}{l}\text { Switch } \\
\text { Cost } \\
\text { Verbal }\end{array}$ & $\begin{array}{l}\text { Switch } \\
\text { Cost } \\
\text { Low } \\
\text { Verbal }\end{array}$ & $\begin{array}{l}\text { 1-Back } \\
\text { Digits }\end{array}$ & $\begin{array}{l}\text { 2-Back } \\
\text { Digits }\end{array}$ & $\begin{array}{c}\text { 1-Back } \\
\text { Fruit }\end{array}$ & $\begin{array}{l}\text { 2-Back } \\
\text { Fruit }\end{array}$ & $\begin{array}{l}\text { 1-Back } \\
\text { Spatial }\end{array}$ & $\begin{array}{l}\text { 2-Back } \\
\text { Spatial }\end{array}$ & $\begin{array}{c}\text { WCST } \\
\text { Category }\end{array}$ & $\begin{array}{l}\text { WCST } \\
\text { Concept } \\
\text { Respons }\end{array}$ \\
\hline \multirow{2}{*}{$\begin{array}{l}\text { Camel and Cactus } \\
\text { Test }\end{array}$} & Spearman's rho & -0.055 & -0.762 & -0.037 & -0.573 & 0.201 & 0.323 & -0.689 & 0.305 & 0.073 & 0.11 & 0.052 & 0.372 & 0.398 & 0.695 & 0.441 & 0.53 \\
\hline & $p$-value & 0.88 & 0.01 & 0.92 & 0.083 & 0.577 & 0.362 & 0.028 & 0.392 & 0.841 & 0.763 & 0.887 & 0.29 & 0.255 & 0.026 & 0.202 & 0.115 \\
\hline \multirow{2}{*}{$\begin{array}{l}\text { Auditory } \\
\text { Comprehension }\end{array}$} & Spearman's rho & -0.152 & -0.255 & -0.827 & -0.146 & 0.711 & 0.486 & 0.207 & 0.401 & 0.195 & 0.164 & 0.204 & -0.158 & 0.335 & -0.134 & -0.08 & -0.505 \\
\hline & $p$-value & 0.675 & 0.476 & 0.003 & 0.688 & 0.021 & 0.154 & 0.567 & 0.25 & 0.59 & 0.65 & 0.571 & 0.663 & 0.343 & 0.713 & 0.826 & 0.137 \\
\hline \multirow{2}{*}{$\begin{array}{l}\text { Written } \\
\text { Comprehension }\end{array}$} & Spearman's rho & -0.47 & -0.537 & -0.457 & -0.445 & 0.707 & 0.683 & 0.226 & 0.72 & 0.488 & 0.238 & 0.361 & 0.146 & 0.489 & 0.159 & 0.006 & -0.226 \\
\hline & p-value & 0.171 & 0.11 & 0.184 & 0.197 & 0.022 & 0.03 & 0.531 & 0.019 & 0.153 & 0.508 & 0.306 & 0.687 & 0.151 & 0.662 & 0.986 & 0.531 \\
\hline \multirow[t]{2}{*}{ Verbal Fluency } & Spearman's rho & -0.067 & -0.661 & 0.127 & -0.467 & -0.03 & -0.055 & -0.539 & -0.139 & 0.212 & 0.188 & 0.407 & 0.648 & 0.584 & 0.915 & 0.841 & 0.697 \\
\hline & $p$-value & 0.865 & 0.044 & 0.733 & 0.178 & 0.946 & 0.892 & 0.113 & 0.707 & 0.56 & 0.608 & 0.243 & 0.049 & 0.077 & $<.001$ & 0.002 & 0.031 \\
\hline \multirow{2}{*}{$\begin{array}{l}\text { Picture } \\
\text { Description }\end{array}$} & Spearman's rho & 0.018 & -0.771 & 0.061 & -0.71 & 0.086 & 0.073 & -0.391 & -0.141 & 0.22 & 0.183 & 0.313 & 0.807 & 0.626 & 0.844 & 0.573 & 0.557 \\
\hline & $p$-value & 0.96 & 0.009 & 0.867 & 0.022 & 0.814 & 0.84 & 0.263 & 0.698 & 0.541 & 0.612 & 0.379 & 0.005 & 0.053 & 0.002 & 0.084 & 0.095 \\
\hline \multirow[t]{2}{*}{ Object Naming } & Spearman's rho & -0.345 & -0.685 & -0.2 & -0.394 & 0.236 & 0.115 & -0.309 & 0.042 & 0.139 & 0.442 & 0.365 & 0.37 & 0.547 & 0.709 & 0.571 & 0.673 \\
\hline & $p$-value & 0.331 & 0.035 & 0.584 & 0.263 & 0.514 & 0.759 & 0.387 & 0.919 & 0.707 & 0.204 & 0.3 & 0.296 & 0.102 & 0.028 & 0.085 & 0.039 \\
\hline \multirow[t]{2}{*}{ Repetition } & Spearman's rho & 0.297 & -0.152 & -0.394 & -0.285 & 0.188 & 0.079 & -0.079 & -0.2 & -0.164 & 0.164 & 0.024 & 0.212 & 0.207 & 0.152 & 0.227 & 0.248 \\
\hline & $p$-value & 0.407 & 0.682 & 0.263 & 0.427 & 0.608 & 0.838 & 0.838 & 0.584 & 0.657 & 0.657 & 0.947 & 0.56 & 0.567 & 0.682 & 0.528 & 0.492 \\
\hline \multirow[t]{2}{*}{ Reading } & Spearman's rho & -0.407 & -0.839 & -0.201 & -0.498 & 0.328 & 0.219 & -0.286 & 0.14 & 0.353 & 0.413 & 0.552 & 0.553 & 0.756 & 0.863 & 0.64 & 0.584 \\
\hline & $p$-value & 0.243 & 0.002 & 0.578 & 0.143 & 0.354 & 0.544 & 0.424 & 0.7 & 0.318 & 0.235 & 0.098 & 0.097 & 0.011 & 0.001 & 0.046 & 0.077 \\
\hline
\end{tabular}

Correction for multiple comparisons: These correlations were completed post-hoc following reviewer comments on the manuscript. For that reason, a correction for multiple comparisons is applied. Each background measure is correlated against 16 measures of Executive Function (general and computerised), giving a Bonferroni corrected p-value of $0.05 / 16=0.003$. Correlations which pass this correction are in shaded and in bold. Correlations that approach significance are shaded only. 
Table A2: Correlation Matrix of performance on computerised executive control tasks for Control participants

\begin{tabular}{|c|c|c|c|c|c|c|c|c|c|c|c|c|c|c|c|}
\hline & & $\begin{array}{l}\text { Stroop } \\
\text { Verbal }\end{array}$ & $\begin{array}{l}\text { Stroop } \\
\text { Low } \\
\text { Verbal }\end{array}$ & $\begin{array}{l}\text { Flanker } \\
\text { Verbal }\end{array}$ & $\begin{array}{c}\text { Flanker } \\
\text { Low } \\
\text { Verbal }\end{array}$ & $\begin{array}{l}\text { Mix Cost } \\
\text { Verbal }\end{array}$ & $\begin{array}{l}\text { Mix Cost } \\
\text { Low } \\
\text { Verbal }\end{array}$ & $\begin{array}{l}\text { Switch } \\
\text { Cost } \\
\text { Verbal }\end{array}$ & $\begin{array}{c}\text { Switch } \\
\text { Cost } \\
\text { Low } \\
\text { Verbal }\end{array}$ & $\begin{array}{l}\text { 1-Back } \\
\text { Digits }\end{array}$ & $\begin{array}{l}\text { 2-Back } \\
\text { Digits }\end{array}$ & $\begin{array}{l}\text { 1-Back } \\
\text { Fruit }\end{array}$ & $\begin{array}{c}\text { 2-Back } \\
\text { Fruit }\end{array}$ & $\begin{array}{l}\text { 1-Back } \\
\text { Spatial }\end{array}$ & $\begin{array}{l}\text { 2-Back } \\
\text { Spatial }\end{array}$ \\
\hline \multirow[t]{2}{*}{ Stroop Verbal } & Spearman's rho & $\overline{-}$ & & & & & & & & & & & & & \\
\hline & $p$-value & - & & & & & & & & & & & & & \\
\hline \multirow{2}{*}{$\begin{array}{l}\text { Stroop Low } \\
\text { Verbal }\end{array}$} & Spearman's rho & 0.033 & - & & & & & & & & & & & & \\
\hline & $p$-value & 0.916 & - & & & & & & & & & & & & \\
\hline \multirow[t]{2}{*}{ Flanker Verbal } & Spearman's rho & 0.059 & 0.037 & - & & & & & & & & & & & \\
\hline & $p$-value & 0.844 & 0.904 & - & & & & & & & & & & & \\
\hline \multirow{2}{*}{$\begin{array}{l}\text { Flanker Low } \\
\text { Verbal }\end{array}$} & Spearman's rho & 0.09 & 0.051 & 0.429 & - & & & & & & & & & & \\
\hline & $p$-value & 0.762 & 0.868 & 0.128 & - & & & & & & & & & & \\
\hline \multirow[t]{2}{*}{ Mix Cost Verbal } & Spearman's rho & 0.226 & 0.108 & 0.037 & -0.319 & - & & & & & & & & & \\
\hline & $p$-value & 0.436 & 0.716 & 0.904 & 0.267 & - & & & & & & & & & \\
\hline \multirow{2}{*}{$\begin{array}{l}\text { Mix Cost Low } \\
\text { Verbal }\end{array}$} & Spearman's rho & -0.081 & -0.011 & 0.073 & -0.301 & 0.578 & - & & & & & & & & \\
\hline & $p$-value & 0.785 & 0.976 & 0.808 & 0.295 & 0.033 & - & & & & & & & & \\
\hline \multirow{2}{*}{$\begin{array}{l}\text { Switch Cost } \\
\text { Verbal }\end{array}$} & Spearman's rho & -0.644 & -0.002 & 0.332 & 0.266 & -0.156 & 0.358 & - & & & & & & & \\
\hline & $p$-value & 0.015 & 1 & 0.246 & 0.357 & 0.594 & 0.209 & - & & & & & & & \\
\hline \multirow{2}{*}{$\begin{array}{l}\text { Switch Cost Low } \\
\text { Verbal }\end{array}$} & Spearman's rho & -0.503 & 0.147 & -0.125 & -0.156 & -0.125 & 0.108 & 0.407 & - & & & & & & \\
\hline & $p$-value & 0.069 & 0.616 & 0.671 & 0.594 & 0.671 & 0.716 & 0.15 & - & & & & & & \\
\hline \multirow[t]{2}{*}{ 1-Back Digits } & Spearman's rho & 0.238 & 0.452 & 0.069 & 0.29 & -0.085 & -0.697 & -0.363 & -0.325 & - & & & & & \\
\hline & $p$-value & 0.412 & 0.105 & 0.815 & 0.315 & 0.774 & 0.006 & 0.202 & 0.257 & - & & & & & \\
\hline \multirow[t]{2}{*}{ 2-Back Digits } & Spearman's rho & -0.158 & 0.26 & -0.207 & 0.257 & -0.271 & -0.433 & -0.095 & 0.013 & 0.371 & - & & & & \\
\hline & $p$-value & 0.589 & 0.37 & 0.478 & 0.374 & 0.349 & 0.122 & 0.748 & 0.964 & 0.191 & - & & & & \\
\hline \multirow[t]{2}{*}{ 1-Back Fruit } & Spearman's rho & -0.452 & 0.465 & 0.159 & 0.187 & -0.101 & -0.289 & 0.377 & -0.059 & 0.443 & 0.225 & - & & & \\
\hline & $p$-value & 0.105 & 0.094 & 0.588 & 0.522 & 0.73 & 0.317 & 0.184 & 0.84 & 0.113 & 0.439 & - & & & \\
\hline
\end{tabular}




\begin{tabular}{|c|c|c|c|c|c|c|c|c|c|c|c|c|c|c|c|}
\hline Table A2 Continued & & $\begin{array}{l}\text { Stroop } \\
\text { Verbal }\end{array}$ & $\begin{array}{l}\text { Stroop } \\
\text { Low } \\
\text { Verbal }\end{array}$ & $\begin{array}{l}\text { Flanker } \\
\text { Verbal }\end{array}$ & $\begin{array}{c}\text { Flanker } \\
\text { Low } \\
\text { Verbal }\end{array}$ & $\begin{array}{l}\text { Mix Cost } \\
\text { Verbal }\end{array}$ & $\begin{array}{l}\text { Mix Cost } \\
\text { Low } \\
\text { Verbal }\end{array}$ & $\begin{array}{c}\text { Switch } \\
\text { Cost } \\
\text { Verbal }\end{array}$ & $\begin{array}{c}\text { Switch } \\
\text { Cost } \\
\text { Low } \\
\text { Verbal } \\
\end{array}$ & $\begin{array}{l}\text { 1-Back } \\
\text { Digits }\end{array}$ & $\begin{array}{l}\text { 2-Back } \\
\text { Digits }\end{array}$ & $\begin{array}{c}\text { 1-Back } \\
\text { Fruit }\end{array}$ & $\begin{array}{c}\text { 2-Back } \\
\text { Fruit }\end{array}$ & $\begin{array}{l}\text { 1-Back } \\
\text { Spatial }\end{array}$ & $\begin{array}{l}\text { 2-Back } \\
\text { Spatial }\end{array}$ \\
\hline \multirow[t]{2}{*}{ 2-Back Fruit } & Spearman's rho & -0.037 & 0.449 & -0.213 & -0.018 & -0.429 & -0.607 & -0.202 & 0.194 & 0.472 & 0.584 & 0.26 & - & & \\
\hline & $p$-value & 0.899 & 0.107 & 0.464 & 0.952 & 0.126 & 0.021 & 0.488 & 0.507 & 0.089 & 0.028 & 0.369 & - & & \\
\hline \multirow[t]{2}{*}{ 1-Back Spatial } & Spearman's rho & -0.313 & 0.337 & -0.013 & 0.004 & 0.002 & -0.514 & -0.225 & -0.049 & 0.565 & 0.28 & 0.606 & 0.457 & - & \\
\hline & $p$-value & 0.276 & 0.238 & 0.964 & 0.988 & 0.994 & 0.06 & 0.439 & 0.869 & 0.035 & 0.332 & 0.022 & 0.1 & - & \\
\hline \multirow[t]{2}{*}{ 2-Back Spatial } & Spearman's rho & 0.086 & 0.618 & 0.231 & 0.317 & -0.246 & -0.374 & 0.035 & -0.119 & 0.426 & 0.174 & 0.59 & 0.498 & 0.511 & - \\
\hline & $p$-value & 0.771 & 0.018 & 0.427 & 0.27 & 0.396 & 0.188 & 0.905 & 0.686 & 0.129 & 0.552 & 0.026 & 0.07 & 0.062 & - \\
\hline
\end{tabular}

Correction for multiple comparisons: These correlations were completed post-hoc following reviewer comments on the manuscript. For that reason, a correction for multiple comparisons is applied. Each measure is correlated against 13 other measures, giving a Bonferroni corrected pvalue of $0.05 / 13=0.004$. Correlations which pass this correction are shaded and in bold. Correlations that approach significance are shaded only 
Table A3: Correlation Matrix of performance on computerised executive control tasks for participants with Aphasia

\begin{tabular}{|c|c|c|c|c|c|c|c|c|c|c|c|c|c|c|c|}
\hline & & $\begin{array}{l}\text { Stroop } \\
\text { Verbal }\end{array}$ & $\begin{array}{l}\text { Stroop } \\
\text { Low } \\
\text { Verbal }\end{array}$ & $\begin{array}{l}\text { Flanker } \\
\text { Verbal }\end{array}$ & $\begin{array}{l}\text { Flanker } \\
\text { Low } \\
\text { Verbal }\end{array}$ & $\begin{array}{l}\text { Mix Cost } \\
\text { Verbal }\end{array}$ & $\begin{array}{l}\text { Mix Cost } \\
\text { Low } \\
\text { Verbal }\end{array}$ & $\begin{array}{c}\text { Switch } \\
\text { Cost } \\
\text { Verbal }\end{array}$ & $\begin{array}{l}\text { Switch } \\
\text { Cost } \\
\text { Low } \\
\text { Verbal }\end{array}$ & $\begin{array}{l}\text { 1-Back } \\
\text { Digits }\end{array}$ & $\begin{array}{l}\text { 2-Back } \\
\text { Digits }\end{array}$ & $\begin{array}{c}\text { 1-Back } \\
\text { Fruit }\end{array}$ & $\begin{array}{l}\text { 2-Back } \\
\text { Fruit }\end{array}$ & $\begin{array}{l}\text { 1-Back } \\
\text { Spatial }\end{array}$ & $\begin{array}{l}\text { 2-Back } \\
\text { Spatial }\end{array}$ \\
\hline \multirow[t]{2}{*}{ Stroop Verbal } & Spearman's rho & - & & & & & & & & & & & & & \\
\hline & $p$-value & - & & & & & & & & & & & & & \\
\hline \multirow{2}{*}{$\begin{array}{l}\text { Stroop Low } \\
\text { Verbal }\end{array}$} & Spearman's rho & 0.394 & - & & & & & & & & & & & & \\
\hline & $p$-value & 0.263 & - & & & & & & & & & & & & \\
\hline \multirow[t]{2}{*}{ Flanker Verbal } & Spearman's rho & 0.079 & 0.2 & - & & & & & & & & & & & \\
\hline & $p$-value & 0.838 & 0.584 & - & & & & & & & & & & & \\
\hline \multirow[t]{2}{*}{$\begin{array}{l}\text { Flanker Low } \\
\text { Verbal }\end{array}$} & Spearman's rho & 0.2 & 0.733 & 0.224 & - & & & & & & & & & & \\
\hline & $p$-value & 0.584 & 0.021 & 0.537 & - & & & & & & & & & & \\
\hline \multirow[t]{2}{*}{ Mix Cost Verbal } & Spearman's rho & -0.333 & -0.43 & -0.903 & -0.503 & - & & & & & & & & & \\
\hline & $p$-value & 0.349 & 0.218 & $<.001$ & 0.143 & - & & & & & & & & & \\
\hline \multirow{2}{*}{$\begin{array}{l}\text { Mix Cost Low } \\
\text { Verbal }\end{array}$} & Spearman's rho & -0.103 & -0.321 & -0.794 & -0.43 & 0.903 & - & & & & & & & & \\
\hline & $p$-value & 0.785 & 0.368 & 0.01 & 0.218 & $<.001$ & - & & & & & & & & \\
\hline \multirow{2}{*}{$\begin{array}{l}\text { Switch Cost } \\
\text { Verbal }\end{array}$} & Spearman's rho & -0.224 & 0.345 & -0.37 & 0.03 & 0.358 & 0.188 & - & & & & & & & \\
\hline & $p$-value & 0.537 & 0.331 & 0.296 & 0.946 & 0.313 & 0.608 & - & & & & & & & \\
\hline \multirow[t]{2}{*}{$\begin{array}{l}\text { Switch Cost Low } \\
\text { Verbal }\end{array}$} & Spearman's rho & -0.285 & -0.236 & -0.636 & -0.212 & 0.782 & 0.915 & 0.079 & - & & & & & & \\
\hline & $p$-value & 0.427 & 0.514 & 0.054 & 0.56 & 0.012 & $<.001$ & 0.838 & - & & & & & & \\
\hline \multirow[t]{2}{*}{ 1-Back Digits } & Spearman's rho & -0.673 & -0.442 & -0.248 & -0.612 & 0.576 & 0.43 & 0.297 & 0.418 & - & & & & & \\
\hline & $p$-value & 0.039 & 0.204 & 0.492 & 0.066 & 0.088 & 0.218 & 0.407 & 0.232 & - & & & & & \\
\hline \multirow[t]{2}{*}{ 2-Back Digits } & Spearman's rho & -0.806 & -0.358 & -0.212 & -0.503 & 0.442 & 0.2 & 0.273 & 0.212 & 0.77 & - & & & & \\
\hline & $\mathrm{p}$-value & 0.008 & 0.313 & 0.56 & 0.143 & 0.204 & 0.584 & 0.448 & 0.56 & 0.014 & - & & & & \\
\hline
\end{tabular}




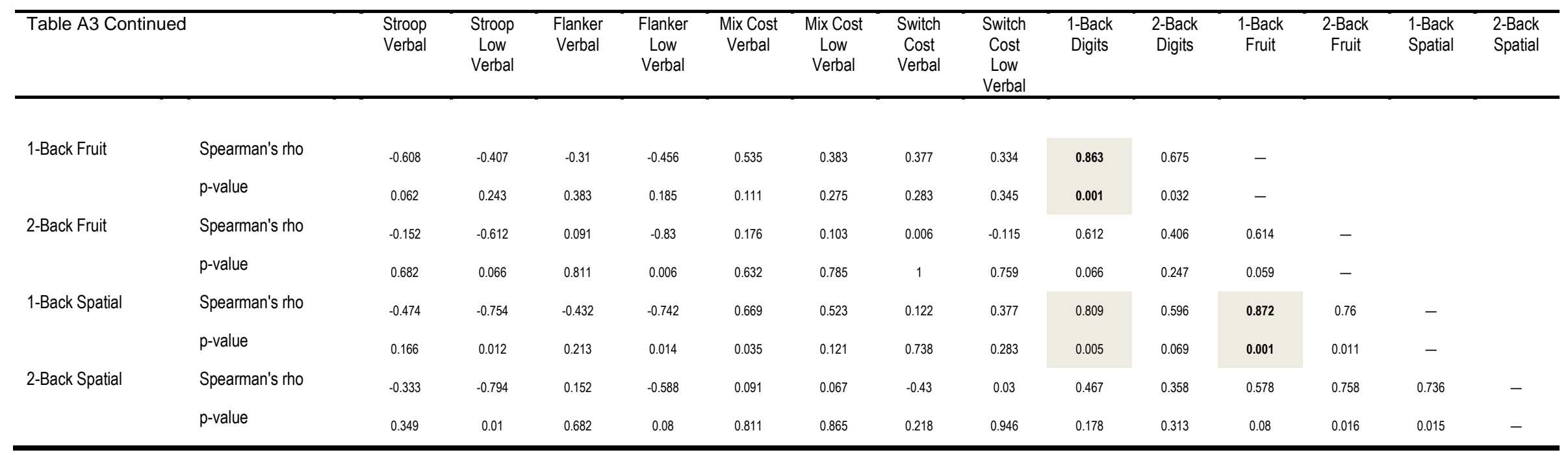

Correction for multiple comparisons: These correlations were completed post-hoc following reviewer comments on the manuscript. For that reason, a correction for multiple comparisons is applied. Each measure is correlated against 13 other measures, giving a Bonferroni corrected pvalue of $0.05 / 13=0.004$. Correlations which pass this correction are in bold. Correlations which approach significance are shaded only. 
Table A4: Correlation matrix of performance on specific and general executive control tasks for participants with Aphasia

\begin{tabular}{|c|c|c|c|c|c|c|c|}
\hline & & $\begin{array}{c}\text { WCST } \\
\text { Categories }\end{array}$ & $\begin{array}{c}\text { WCST } \\
\text { Conceptual } \\
\text { Responses }\end{array}$ & $\begin{array}{l}\text { Corsi } \\
\text { Forwards }\end{array}$ & $\begin{array}{c}\text { Corsi } \\
\text { Backwards }\end{array}$ & $\begin{array}{l}\text { Spoken } \\
\text { Forwards }\end{array}$ & $\begin{array}{c}\text { Spoken } \\
\text { Backwards }\end{array}$ \\
\hline \multirow[t]{2}{*}{ Stroop Verbal } & Spearman's rho & -0.184 & -0.2 & 0.318 & -0.148 & 0.239 & 0.458 \\
\hline & $p$-value & 0.611 & 0.584 & 0.371 & 0.683 & 0.506 & 0.184 \\
\hline \multirow[t]{2}{*}{ Stroop Low Verbal } & Spearman's rho & -0.405 & -0.273 & -0.175 & -0.488 & -0.42 & -0.28 \\
\hline & $p$-value & 0.246 & 0.448 & 0.63 & 0.153 & 0.227 & 0.434 \\
\hline \multirow[t]{2}{*}{ Flanker Verbal } & Spearman's rho & 0.086 & 0.394 & 0.168 & -0.179 & -0.278 & -0.458 \\
\hline & $p$-value & 0.813 & 0.263 & 0.642 & 0.621 & 0.437 & 0.184 \\
\hline \multirow[t]{2}{*}{ Flanker Low Verbal } & Spearman's rho & -0.35 & -0.188 & -0.467 & -0.617 & 0.084 & -0.21 \\
\hline & $p$-value & 0.322 & 0.608 & 0.173 & 0.057 & 0.817 & 0.561 \\
\hline \multirow[t]{2}{*}{ Mix Cost Verbal } & Spearman's rho & 0.049 & -0.273 & 0.056 & 0.445 & 0.149 & 0.299 \\
\hline & $p$-value & 0.893 & 0.448 & 0.878 & 0.198 & 0.682 & 0.402 \\
\hline \multirow[t]{2}{*}{ Mix Cost Low Verbal } & Spearman's rho & 0.061 & -0.188 & 0.28 & 0.549 & 0.239 & 0.394 \\
\hline & $p$-value & 0.866 & 0.608 & 0.432 & 0.1 & 0.506 & 0.26 \\
\hline Switch Cost Verbal & Spearman's rho & -0.178 & -0.345 & 0.062 & -0.161 & -0.614 & -0.432 \\
\hline & $p$-value & 0.623 & 0.331 & 0.864 & 0.658 & 0.059 & 0.212 \\
\hline \multirow{2}{*}{$\begin{array}{l}\text { Switch Cost Low } \\
\text { Verbal }\end{array}$} & Spearman's rho & 0.031 & -0.139 & 0.143 & 0.469 & 0.226 & 0.242 \\
\hline & $p$-value & 0.933 & 0.707 & 0.693 & 0.171 & 0.53 & 0.501 \\
\hline \multirow[t]{2}{*}{ 1-Back Digits } & Spearman's rho & 0.368 & 0.055 & 0.187 & 0.716 & -0.304 & -0.203 \\
\hline & $p$-value & 0.295 & 0.892 & 0.605 & 0.02 & 0.393 & 0.573 \\
\hline \multirow[t]{2}{*}{ 2-Back Digits } & Spearman's rho & 0.27 & 0.285 & -0.28 & 0.333 & -0.394 & -0.242 \\
\hline & $p$-value & 0.451 & 0.427 & 0.432 & 0.347 & 0.259 & 0.501 \\
\hline \multirow[t]{2}{*}{ 1-Back Fruit } & Spearman's rho & 0.658 & 0.292 & 0.075 & 0.653 & -0.227 & -0.019 \\
\hline & $p$-value & 0.038 & 0.413 & 0.837 & 0.041 & 0.528 & 0.958 \\
\hline \multirow[t]{2}{*}{ 2-Back Fruit } & Spearman's rho & 0.606 & 0.237 & 0.203 & 0.756 & 0.091 & 0.23 \\
\hline & $p$-value & 0.063 & 0.51 & 0.573 & 0.011 & 0.803 & 0.524 \\
\hline
\end{tabular}




\begin{tabular}{|c|c|c|c|c|c|c|c|}
\hline Table A4 continued & & $\begin{array}{c}\text { WCST } \\
\text { Categories }\end{array}$ & $\begin{array}{c}\text { WCST } \\
\text { Conceptual } \\
\text { Responses }\end{array}$ & $\begin{array}{l}\text { Corsi } \\
\text { Forwards }\end{array}$ & $\begin{array}{c}\text { Corsi } \\
\text { Backwards }\end{array}$ & $\begin{array}{l}\text { Spoken } \\
\text { Forwards }\end{array}$ & $\begin{array}{c}\text { Spoken } \\
\text { Backwards }\end{array}$ \\
\hline \multirow[t]{2}{*}{ 1-Back Spatial } & Spearman's rho & 0.606 & 0.237 & 0.203 & 0.756 & 0.091 & 0.23 \\
\hline & $p$-value & 0.063 & 0.51 & 0.573 & 0.011 & 0.803 & 0.524 \\
\hline \multirow[t]{2}{*}{ 2-Back Spatial } & Spearman's rho & 0.804 & 0.685 & 0.187 & 0.648 & 0.239 & 0.267 \\
\hline & $p$-value & 0.005 & 0.035 & 0.605 & 0.043 & 0.506 & 0.456 \\
\hline WCST Categories & Spearman's rho & - & 0.755 & 0.101 & 0.519 & -0.039 & 0.402 \\
\hline \multirow{3}{*}{$\begin{array}{l}\text { WCST Conceptual } \\
\text { Responses }\end{array}$} & $p$-value & - & 0.012 & 0.781 & 0.124 & 0.914 & 0.249 \\
\hline & Spearman's rho & & - & -0.037 & 0.241 & -0.058 & 0.159 \\
\hline & $p$-value & & - & 0.918 & 0.503 & 0.873 & 0.661 \\
\hline \multirow[t]{2}{*}{ Corsi Forwards } & Spearman's rho & & & - & 0.467 & -0.126 & -0.059 \\
\hline & $p$-value & & & - & 0.174 & 0.728 & 0.872 \\
\hline \multirow[t]{2}{*}{ Corsi Backwards } & Spearman's rho & & & & - & 0.151 & 0.243 \\
\hline & $p$-value & & & & - & 0.676 & 0.499 \\
\hline \multirow[t]{2}{*}{ Spoken Forwards } & Spearman's rho & & & & & - & 0.556 \\
\hline & $p$-value & & & & & - & 0.095 \\
\hline
\end{tabular}

Correction for multiple comparisons: These correlations were completed post-hoc following reviewer comments on the manuscript. For that reason, a correction for multiple comparisons is applied. Each general measure is correlated against 19 other measures, giving a Bonferroni corrected p-value of $0.05 / 19=0.003$. Correlations which pass this correction are shaded and in bold. Correlations that approach significance are shaded only. 